\title{
ENTICE: \\ ENDOGENOUS TECHNOLOGICAL CHANGE IN THE DICE MODEL OF GLOBAL WARMING
}

\author{
David Popp \\ Working Paper 9762 \\ http://www.nber.org/papers/w9762

\section{NATIONAL BUREAU OF ECONOMIC RESEARCH 1050 Massachusetts Avenue Cambridge, MA 02138} \\ June 2003
}

The author thanks William Nordhaus, Charles Kolstad, Larry Goulder, Ian Sue Wing, and two anonymous referees for helpful discussions concerning this paper. Yixin Dai provided excellent research assistance. Financial support for this work was provided by the National Science Foundation under grant number SES0001679. The views expressed herein are those of the authors and not necessarily those of the National Bureau of Economic Research.

C2003 by David Popp. All rights reserved. Short sections of text not to exceed two paragraphs, may be quoted without explicit permission provided that full credit including $(\subset$ notice, is given to the source. 
ENTICE: Endogenous Technological Change in the DICE Model of Global Warming David Popp

NBER Working Paper No. 9762

June 2003

JEL No. O33, O41, Q43, Q48

\begin{abstract}
Despite growing empirical evidence of the link between environmental policy and innovation, most economic models of environmental policy treat technology as exogenous. For long-term problems such as climate change, this omission can be significant. In this paper, I modify the DICE model of climate change (Nordhaus 1994, Nordhaus and Boyer 2000) to allow for induced innovation in the energy sector. Ignoring induced technological change overstates the welfare costs of an optimal carbon tax policy by 8.3 percent. However, cost-savings, rather than increased environmental benefits, appear to drive the welfare gains, as the effect of induced innovation on emissions and mean global temperature is small. Sensitivity analysis shows that potential crowding out of other $\mathrm{R} \& \mathrm{D}$ and market failures in the R\&D sector are the most important limiting factors to the potential of induced innovation. Differences in these key assumptions explain much of the variation in the findings of other similar models.
\end{abstract}

\author{
David Popp \\ Department of Public Administration \\ Syracuse University \\ The Maxwell School \\ Syracuse University \\ 400 Eggers Hall \\ Syracuse, NY 13244-1090 \\ and NBER \\ dcpopp@maxwell.syr.edu
}


When studying solutions to long-term environmental problems such as climate change, it is important to consider the role that technological change may play. Nonetheless, most economic models of climate change treat technology as exogenous. Since policies adopted to combat climate change are likely to have a large impact on the pace and direction of technological change, these models miss the important link between policy and innovation. In this paper, I make use of empirical results on technological change in the energy industry (Popp 2002, 2001, 1998, 1997) to incorporate endogenous technological change into the DICE model of climate change (Nordhaus 1994). In the model, technological change that enhances energy efficiency is stimulated by changes in the price of energy, including carbon taxes. I use the new model, named the ENTICE model (for ENdogenous Technological change), to compare the overall global welfare costs of carbon policy to the results of models in which technological change is exogenous. I show that ignoring induced innovation overstates the welfare cost of reducing carbon emissions. However, cost-savings appear to drive the welfare gains, as the effect of induced innovation on emissions and mean global temperature is small. Sensitivity analysis reveals that market imperfections and potential crowding out effects limit the overall effect of endogenous technological change.

To date, few models of climate change include endogenous technological change that affects carbon emissions. The most prominent examples of models with endogenous technological change are Goulder and Schneider (1999), Nordhaus (2002), and Buonanno et al. (2003). However, none of the existing models make use of empirical estimates on the nature of technological change to calibrate the model. I use the estimates obtained in previous work to guide the development and calibration of a model of endogenous technological change that is supported by empirical evidence. 
Although the DICE model is a greatly simplified macroecomic representation of the global economy and the environment, its use offers two advantages for this work. First, because of its relative transparency, sensitivity analysis of key assumptions is straightforward. Existing models of technological change and the environment include differing assumptions about features such as imperfect research markets and the potential crowding out effects of energy R\&D. I use the ENTICE framework to provide a detailed sensitivity analysis of these assumptions. Second, since the DICE model framework explicitly models both the costs and benefits of greenhouse gas reduction, I hope to provide a better understanding of how consideration of endogenous technological change affects the optimal policy decision. One can imagine two offsetting effects of endogenizing R\&D. Increased innovation allows a given abatement target to be achieved more easily, thus lowering the carbon tax needed to meet a given emission target. At the same time, lower abatement costs make greater emissions reductions feasible, offsetting the desire to lower the carbon tax. ${ }^{1}$ Using the DICE model framework, I solve for the optimal path of carbon taxes with and without endogenous technological change.

The paper begins with a review of the literature on induced innovation and the environment. A discussion of existing climate models with induced technological change follows. Section II presents the modifications to the DICE model necessary to endogenize technological change in the energy sector. Two policy simulations are presented in section III: one representing an optimal policy, in which the marginal benefits and marginal costs of carbon emission abatement are equal, and one restricting global emissions to 1995 levels. Section IV includes sensitivity analysis on key assumptions, and uses this analysis to contrast the results of

\footnotetext{
${ }^{1}$ In a theoretical model, Goulder and Mathai (2000) find that the first effect dominates, justifying a lower carbon tax when innovation is considered. Parry (1995) offers a similar conclusion.
} 
ENTICE and other climate change models with endogenous technological change. Section V concludes.

\section{Literature Review}

\section{A. Induced Innovation and Environmental Policy}

In this paper, I endogenize technological change by including policy-induced innovation in the energy sector. The notion of induced innovation was first introduced by Hicks (1932), who noted that changes in factor prices would lead to innovation to economize on usage of the more expensive factor. In the environmental literature, the relationship between innovation and policy has been explored under two broad themes. ${ }^{2}$ Papers such as Magat (1978), Milliman and Prince (1989), and Fisher et al. (1998) use theoretical models to compare the effects of various environmental policy mechanisms (e.g. command and control regulation, emissions taxes, or tradable permits) on environmentally-friendly innovation. In general, these papers predict that market-based policies, such as a tax or tradable permit, will induce more environmentallyfriendly innovation than a command and control policy.

Recently, empirical economists have begun to estimate the effects that prices and environmental policies have on environmentally-friendly innovation. Both Lanjouw and Mody (1996) and Jaffe and Palmer (1997) find correlations between pollution abatement expenditures and measures of environmental innovation. Jaffe and Palmer (1997) estimate a positive elasticity of pollution control R\&D with respect to pollution control expenditures of 0.15 .

Other papers use energy prices and related regulations as the mechanism that induces innovation. Although the observed price changes might not be policy-related, the results can be

\footnotetext{
${ }^{2}$ A comprehensive survey of the literature on technological change and the environment may be found in Jaffe, Newell, and Stavins (2003).
} 
applied to situations where policy affects prices, such as a carbon tax. Using hedonic techniques to study the effect of energy prices and energy efficiency regulations on air conditioners and natural gas water heaters, Newell et al. (1999) find energy prices to have the largest technology inducement effect. However, they do not estimate a price elasticity. Popp (2002) uses patent data from 1970-1994 to estimate a long run price elasticity between energy prices and energy patents of 0.35. Important for long-term modeling, Popp also finds evidence of diminishing returns to this $R \& D$, so that the effect of a carbon tax on $R \& D$ will be smaller in the long run. Finally, Popp (2001) uses the same patent data to estimate the industrial energy savings resulting from new energy patents. The average patent generates approximately 7.9 million dollars over the life of a patent. To put this figure in perspective, consider that an average of 2.25 million dollars of $R \& D$ is spent per patent in these energy fields.

\section{B. Induced Innovation in Climate Change Models}

Despite the growing evidence that environmental policy influences the direction of technological change, few climate change models directly incorporate links between policy and technology. ${ }^{3}$ Those that do typically model innovation in one of two ways. Bottom-up models include a detailed specification of energy systems. These models typically do not include detailed modeling of the overall macroeconomy, and typically model induced technological change in a learning-by-doing framework, in which the costs of various technologies decrease with experience. Examples include Gerlagh and van der Zwaan (2003), Manne and Richels

\footnotetext{
${ }^{3}$ The results of Chakravorty, Roumasset, and Tse (1997) show why considering the link between policy and technological change is important. They present a simulation showing that the development of alternative fuels lowers the projected temperature increases caused by global warming from 3-6 degrees centigrade to just 1-2 degrees centigrade. Unfortunately, they do not model the development of such technologies, but rather assume that they continue to develop at historical rates. Since much of the development of alternatives such as solar energy occurred during the period of high energy prices during the late 1970s, assuming that historical rate of technological progress will continue without policy stimulation is unrealistic, and may lead to overly optimistic results.
} 
(2002), Grübler and Messner (1998), and Messner (1997). Top-down models focus on the links between environmental policy and macroeconomic performance. Endogenous technological change in these models typically comes through accumulated investment in research and development (R\&D). Recent models of this nature include Goulder and Schneider (1999), Nordhaus (2002), and Buonanno et al. (2003). The ENTICE model builds on the work of the top-down models.

Goulder and Schneider's model is a computable general equilibrium (CGE) model including both a carbon-based energy sector and an alternative energy sector. They find induced R\&D lowers the cost of achieving a given abatement target, but also increases the gross costs (costs before accounting for environmental benefits) of the carbon tax, as the economy now responds more elastically to the tax. They do conclude that the net benefits of a carbon tax are larger when induced innovation is considered - the cost of achieving any given level of abatement is lower when induced innovation is included in the model. ${ }^{4}$

Nordhaus (2002) introduces the R\&DICE model, a variant of the global DICE model using a fixed proportions production function to model induced technological change. R\&D is modeled as shifting the minimum level of carbon/energy inputs required for production. Factor substitution is not allowed in the model. As a result, Nordhaus is able to compare the role of induced innovation to the role of factor substitution in reducing greenhouse emissions. However, he is not able to combine the two effects to show how the optimal carbon tax is affected. Nordhaus concludes that induced innovation is less important than factor substitution for reducing greenhouse gas emissions. In comparison, Buonanno et al. (2003) introduce technological change to the RICE model, which is a regional version of the DICE model. They

\footnotetext{
${ }^{4}$ These cost savings can be significant. For example, the cost of achieving a $30 \%$ reduction in cumulative emissions falls by nearly $25 \%$ using their central case parameter values.
} 
find that technological change is able to significantly lower abatement costs in this model, although the exact magnitude varies by region and whether or not trading of emissions rights is allowed.

One key difference in the approaches used by Nordhaus and Buonanno et al. is the assumption each makes about the potential opportunity costs of R\&D. Nordhaus assumes that there is a fixed amount of total R\&D spending in the economy. Thus, any increases in energy sector R\&D must come at the expense of $R \& D$ aimed at increasing the overall level of productivity. In contrast, Buonanno et al. model a single R\&D stock, which accumulates endogenously. The accumulated stock of R\&D has two effects: it increases total factor productivity and decreases the carbon intensity of the economy. Thus, rather than policyinduced R\&D crowding out other research efforts, in their model policy-induced R\&D actually enhances overall productivity as well!

A look at recent data suggests that neither assumption is correct. Figure 1 presents data on energy R\&D and non-energy R\&D performed by U.S. industries from 1972-1998. The data are normalized so that $1982=100$. Although increases in energy R\&D do lead to decreases in non-energy R\&D, there is no evidence of a dollar for dollar tradeoff. ${ }^{5}$ Rather, the data suggest only partial crowding out occurs.

To improve upon the results of these papers, my model includes a specification of production that allows for both endogenous technological change and factor substitution. As such, I am able to study how endogenous technological change affects the optimal policy

\footnotetext{
${ }^{5}$ Further evidence can be found by regressing non-energy R\&D on energy R\&D. Complete crowding out results in a coefficient of -1 on energy R\&D. Using data from 1972-1998, and correcting for autocorrelation, I obtain the following regression results (standard errors in parenthesis): non-energy $R \& D=-9320.351478-0.41$ energy $R \& D+19.82 G D P+\varepsilon$
} (4762.59) (1.09) (0.73) 
decision. In addition, the model will be calibrated based on empirical estimates of energy-saving $\mathrm{R} \& \mathrm{D}$ derived in previous work. These studies show that the reaction of R\&D to changes in energy prices is quick, but that it may not be long-lasting, as there are diminishing returns to R\&D over time. Finally, the model is set up to allow straightforward sensitivity analysis of the opportunity cost of energy R\&D. The results show that assumptions on this opportunity cost have a significant effect on the magnitude of the welfare gains possible from induced innovation.

\section{The Model}

I begin by modifying the latest version of Nordhaus' DICE model (Nordhaus 2000) to accommodate induced technological change. The DICE model (Nordhaus 1994, 2000) is a dynamic growth model of the global economy that includes links between economic activity, carbon emissions, and the climate. A related model, the RICE model, extends the DICE model to include 13 regions of the world. Documentation of the most recent modifications of the model (RICE-99 and DICE-99) can be found in Nordhaus and Boyer (2000). ${ }^{6}$

My model, the ENTICE model (for ENdogenous Technological change), combines features of both models. In particular, following the RICE-99 framework, I model carbon-based energy sources as an input to production, rather than a by-product requiring control. However, I use the global framework of the DICE model, rather than the regional framework of the RICE model. This offers a couple of advantages. Most importantly, a particular goal of this research is to calibrate technological change in a way that is consistent with existing empirical studies. Calibrating a regional model would not only require estimates of induced innovation that varied by region, but also information on flows of knowledge across regions. Given the limited

\footnotetext{
${ }^{6}$ This publication is available on the Internet at: http://www.econ.yale.edu/ nordhaus/homepage/dicemodels.htm.
} 
empirical evidence available, calibrating a regional model is left for future research. In addition, the DICE model is simpler in structure, and thus is more accurate for long-time frames (Nordhaus and Boyer 2000). Because of the long-term nature of technological change, trading off regional detail for greater long-term accuracy seems worthwhile.

In both the DICE and ENTICE models, the goal of the model is to maximize per capita utility, equation (1), subject to the economic constraints below [equations (2)-(10)]. ${ }^{7}$

$$
\max V=\sum_{t=0}^{T} U_{t}\left[c_{t}, L_{t}\right] R_{t}
$$

In this equation, $U_{t}$ represents utility at time $t, c_{t}$ is per capita consumption, $L_{t}$ represents population, and is also the measure of labor inputs. $R_{t}$ is a discount factor to represent the rate of time preference. ${ }^{8}$

The objective function, (1), is maximized subject to the following constraints. First, production is defined. The ENTICE model follows the RICE model by including emissions as an input to the production process. Below, $Q_{t}$ represents output produced at time $t$. Overall technological progress comes through changes in total factor productivity, $A_{t}$. In addition to labor, other inputs are the physical capital stock, $K_{t}$, and $F_{t}$, which represents the level of fossil fuels used at time $t$. The cost of these fuels is $p_{F}$. $E_{t}$ is a measure of effective energy units that

\footnotetext{
${ }^{7}$ Environmental equations remain unchanged from the DICE model, and are not presented here. They are included in an appendix available from the author.

${ }^{8}$ As many economists have recently noted, discount rates that seem appropriate for single-generation projects may be inappropriate for long term projects that span several generations. Although there is no consensus on how to deal with this problem, a constantly declining discount factor is consistent with suggestions that a lower discount rate should be used for the distant future. Thus, following Nordhaus, the pure rate of social time preference, $R$, declines over time to capture uncertainty over future conditions, and is given by $R(t)=\prod_{v=0}^{t}\left[1+R_{0} e^{-g_{r} t}\right]^{10}$, where $g_{R}$ is a parameter defining the growth of $R$ over time. Portney and Weyant (1999) provide a good review of the current debate on discounting for long-term environmental projects.
} 
accounts for both fossil fuel inputs and technological change in the energy sector. The cost of these fossil fuels are subtracted from total output in the ENTICE model: ${ }^{9}$

$$
Q_{t}=A_{t} K_{t}^{\gamma} L_{t}^{1-\gamma-\beta} E_{t}^{\beta}-p_{F} F_{t}
$$

Labor is determined by exogenous population growth. The capital stock, $K_{t}$, equals the sum of current investment, $I_{t}$, and the previous capital stock, adjusted for depreciation, $\delta$ :

$$
K_{t}=I_{t}-\delta K_{t-1}
$$

In equilibrium all output must go to either consumption or investment, so that:

$$
Q_{t}=C_{t}+I_{t}
$$

To begin, consider the case of exogenous technological change only. Following the RICE model, exogenous technological improvement comes through changes in the ratio of carbon emissions per unit of carbon services, $\Phi_{t}$. $\Phi_{t}$ increases over time as defined below, where $g_{t}^{z}$ is the growth rate of $\Phi_{t}$ per decade, and $\delta^{z}$ is the rate of decline of this growth rate. Given this, actual carbon emissions are represented in the model as:

$$
\begin{aligned}
& E_{t}=\frac{F_{t}}{\Phi_{t}}, \text { where } \\
& \Phi_{t}=\exp \left[\left(\frac{g_{t}^{z}}{\delta^{z}}\right)\left(1-\exp \left(-\delta^{z} t\right)\right)\right]
\end{aligned}
$$

The parameters defining $\Phi_{t}$ are calibrated to match the emissions path of the DICE model.

Since the ENTICE model includes carbon-based energy as an input to production, it is necessary to include a cost for this input. Following the RICE model, the price of carbon is the sum of the marginal cost of carbon extraction, $q_{F}$, and a markup that captures the difference

\footnotetext{
${ }^{9}$ Energy consumption, represented by fossil fuel usage, $F$, is measured in tons of carbon. The price of fossil fuels is thus the price per ton of carbon.
} 
between consumer prices and the marginal costs of extraction. Nordhaus notes that this markup includes transportation costs, distribution costs, and current taxes.

$$
P_{F}=q_{F}+\text { markup }
$$

In the RICE model, the markup varies by region. To adopt this parameter for the global ENTICE model, I use a weighted average of regional markups from RICE, weighting by each region's share of total carbon consumption in the base year. This value equals 163.29.

Following Nordhaus, the marginal cost function, $q_{F}$, takes the following form:

$$
q_{F}=113+700\left[\mathrm{CumC}_{t} / \mathrm{CumC}^{*}\right]^{4}
$$

$\mathrm{CumC}_{t}$ represents cumulative carbon extraction up to year $t$, and $C u m C^{*}$ represents the maximum possible extraction. In this equation, the marginal cost independent of exhaustion is $\$ 113$ per ton. Marginal costs increase as extractin increases. Note that the price equation is extremely convex - the carbon price equation is relatively elastic in the short run. ${ }^{10}$

Having added carbon fuels as an input to production in the DICE model, the next step is to add induced technological change to the ENTICE model. For this, I create a stock of knowledge that relates to energy efficiency. Similar to a physical capital stock, this knowledge capital stock is created by the accumulation of previous research and development (R\&D) in the manner described below.

$$
H_{E, t}=h\left(R_{E, t}\right)+\left(1-\delta_{H}\right) \cdot H_{E, t-1}, \quad i=A, E
$$

Equation (8) states that the stock of knowledge, $H_{E, t}$, increases due to increases in $R \& D$ net depreciation of old knowledge. The function $h\left(R_{E, t}\right)$ is the innovation possibility frontier. It models the process by which energy $\mathrm{R} \& \mathrm{D}, R_{E, t}$, creates new knowledge. The parameter $\delta_{H}$ allows for the possibility of knowledge decay over time.

\footnotetext{
${ }^{10}$ A more detailed discussion of the derivation of these parameters can be found in Nordhaus and Boyer (2000).
} 
As noted earlier, empirical work suggests that there are diminishing returns to energy research over time. The assumption here is that, since energy $R \& D$ is specialized within a given field, it becomes more and more difficult to find new inventions as the knowledge frontier moves out. Thus, any functional form for the innovation possibility frontier must have the following properties. First, the derivative of $h$ with respect to $R$ should be positive, but the second derivative should be negative, so that there are diminishing returns to research at any given time. In addition, the derivative $\partial^{2} H / \partial R \partial H$ should be negative, so that there are diminishing returns to research over time. One functional form that satisfies these assumptions is a constant elasticity relationship between research and knowledge:

$$
h\left(R_{E, t}\right)=a R_{E, t}^{b} H_{E, t}^{\phi}
$$

A similar innovation possibilities frontier is often used in the endogenous growth literature. ${ }^{11}$ Equation (9) satisfies the two assumptions regarding diminishing returns to R\&D as long as both $b$ and $\phi$ are between 0 and 1.

Having defined this stock of knowledge, total energy use is now modeled as a combination of carbon-based fossil fuels and energy-related human capital. Energy-based human capital can be thought of as knowledge that allows output to be produced with less carbon emissions, either because of increased energy efficiency or more effective emissions control:

$$
E_{t}=\left[\alpha_{H} H_{E, t}^{\rho}+\left(\frac{F_{t}}{\alpha_{\Phi} \Phi_{t}}\right)^{\rho}\right]^{1 / \rho}, \quad \rho \leq 1
$$

\footnotetext{
${ }^{11}$ See, for example, Jones (1995) and Porter and Stern (2000). Romer's (1990) original specification of the endogenous growth model is a special case of this where $\phi=1$. By setting $\phi=1$, Romer generates increasing returns to knowledge over time. While this may be appropriate for macro-level $R \& D$, for more specific $R \& D$ in a given field, it is reasonable to assume that the returns fall over time as the pool of potential ideas in the field dries up [see, for example, Griliches (1989 p. 317)]. Popp (2002) uses energy patent citations to provide evidence of diminishing returns to energy R\&D.
} 
Equation (10) states that the total energy requirements for production must be met either by the use of fossil fuel or by technological advances that substitute for fossil fuels. The technological advances may be thought of as improvements in the energy efficiency of existing production processes, as fuels that are substitutes for fossil fuels, or as improvements in emissions control technology. In this equation, $\rho$ represents the ease of substitution between fossil fuels and knowledge. The case of perfect substitution is $\rho=1$. The elasticity of substitution between them is $1 /(1-\rho) . \quad \alpha_{H}$ is a scaling factor that determines the level of energy savings resulting from new energy knowledge. $\alpha_{\Phi}$ is a scaling factor for any remaining exogenous reductions in carbon intensity.

The scaling factor $\alpha_{\Phi}$ is included to allow for other potential exogenous changes that may lower carbon intensity (the carbon/output ratio). The R\&D modeled through the innovation possibilities frontier captures purposeful short-term efforts to improve energy efficiency or otherwise reduce carbon emissions. However, such R\&D is not the only way in which carbon intensity falls over time. Examples of other potential influences on carbon intensity include changes in consumption patterns and switching to less carbon intensive fuels (e.g. from coal to oil to natural gas) over time. Because the DICE model and its variants are a one-sector macroeconomic growth model, such changes are not explicitly modeled. As Nordhaus calibrates exogenous technological change based on historical rates of decarbonization, it is impossible to separate out these effects from the effects of $R \& D$ in his rate of exogenous technological change. Removing these exogenous influences from the model completely would not only remove the results of any energy R\&D included in Nordhaus' calibration, but also would remove the effect 
of these other long-term changes in carbon intensity. As a result, long-run emissions simulated without any exogenous decline in carbon-intensity are unrealistically high. ${ }^{12}$

Because of the public goods nature of knowledge, the role of market failures in $R \& D$ must be considerd. Virtually all empirical studies of $R \& D$ find that the social returns to $R \& D$ are greater than the private returns to $R \& D .{ }^{13}$ Since firms will invest until the private rates of return to $R \& D$ are equal to the rates of returns on other investments, underinvestment in $R \& D$ will occur. To model the positive externalities that result from the creation of new knowledge, the private return on $R \& D$ investment is constrained to be four times that of investment in physical capital. $^{14}$

Finally, we need to account for the opportunity cost of R\&D. First, equation (4) is modified to include R\&D:

$$
Q_{t}=C_{t}+I_{t}+R_{E, t}
$$

Second, the potential effects of crowding out must be considered. The opportunity cost of a dollar of energy R\&D is that one less dollar is available for any of three possible activities: consumption, physical investment, or investment in other R\&D. The opportunity costs of the first two are simply valued at one dollar. However, since the social rate of return on R\&D is four times higher that of other investment, losing a dollar of other R\&D has the same effect as losing four dollars of other investment. Thus, the price of any research that crowds out other research is four dollars.

\footnotetext{
${ }^{12}$ Fortunately, sensitivity analysis suggests that the percentage of exogenous technological change remaining does not affect the net economic impact of induced technological change. The intuition is that it is the level of R\&D induced between an exogenous and endogenous $R \& D$ simulation that affects this difference. Changing the scaling factor only changes the level of emissions in each simulation, but not the difference between them. This is discussed more thoroughly in the sensitivity analysis presented in section IV.

${ }^{13}$ There is a large body of empirical work that verifies the social returns to R\&D are greater than the private returns. Examples include Mansfield (1977, 1996), Pakes (1985), Jaffe (1986), and Hall (1995).

${ }^{14}$ This is done by calculating the marginal products of physical capital investment and energy $R \& D$, and constraining the latter to be four times higher than the former.
} 
To implement this, four dollars of private investment are subtracted from the physical capital stock for each dollar of R\&D crowded out by energy R\&D, so that the net capital stock is:

$$
K_{t}=\left(I_{t}-4^{*} \text { crowdout* } R_{E, t}\right)-\delta K_{t-1}
$$

where crowdout represents the percentage of other R\&D crowded out by energy R\&D. The base ENTICE model assumes 50\% crowding out.

To calibrate the R\&D sector of the ENTICE model, several new parameter values are needed. These include:

- the initial value of energy research, $R_{E 0}$. This value is 10 billion dollars. ${ }^{15}$

- $\rho$, the substitution parameter in equation (10),

- parameters in the invention possibilities frontier (9): $a, b$, and $\phi$, and

- the initial level of energy human capital, $H_{E 0},{ }^{16}$

- $\alpha_{H}$, the scaling factor for the effect of this human capital, and

- $\alpha_{\Phi}$, the percentage of exogenous reductions in carbon intensity remaining.

I calibrate these parameters to yield results consistent with empirical work on induced innovation in the energy sector. I focus on several key results:

- Estimates of the elasticity of energy R\&D with respect to changes in energy prices suggest that the response is inelastic. Using a distributed lag model, Popp (2002) finds a long run elasticity of 0.35 . In a similar study, Jaffe and Palmer (1997) estimate an

\footnotetext{
${ }^{15}$ To get this value, I begin with an estimated level of total global spending on R\&D of $\$ 500$ billion. This figure is based largely on data from OECD countries. Energy R\&D data is not available on a global basis. However, it is available for the United States. In the U.S., two percent of R\&D spending in 1995 went to energy-related R\&D. The $\$ 10$ billion figure used in this paper is simply two percent of the global level of R\&D. This figure is also close to the initial value of R\&D used by Nordhaus (1999).

${ }^{16}$ Note that, since human capital enters the invention possibilities frontier multiplicatively, the initial value cannot be zero.
} 
elasticity of pollution control R\&D with respect to pollution control expenditures of 0.15 .

- There are diminishing returns to energy R\&D. Although energy prices peaked in 1982, patenting activity in these energy-related technologies began to drop during the late 1970s. Popp (2002) provides evidence that this decline can be explained by diminishing returns to R\&D over time. Thus, the inducement effect of energy prices will fall over time.

- Energy R\&D has a significant impact on energy consumption. Using energy patent data from 13 energy-intensive industries, Popp (2001) finds that each new energy patent leads to 8 million dollars of energy savings. To put this figure in perspective, consider that an average of 2 million dollars of R\&D is spent per patent in these energy fields - suggesting a 4:1 ratio of energy savings to energy R\&D. ${ }^{17}$ This ratio is consistent with other empirical studies, such as those cited in footnote 13.

- Both the response of energy R\&D to price changes and the energy savings resulting from these new technologies occur quickly. Using the lag parameter from a distributed lag regression, Popp (2002) finds that mean lag for the effect of energy prices on energy patenting is 3.7 years, and the median lag is 4.9 . In addition, the energy savings resulting from new patents occur quickly. Popp (2001) estimates rates of decay and diffusion for the knowledge embodied in new patents in 13 industries. It takes just three years for an invention represented by a patent application to have its maximum effect on energy consumption. Since the responses are fairly quick, and

\footnotetext{
${ }^{17}$ Popp (2001) is a micro-level study focusing on specific industries and technologies. Since the industries included are energy-intensive industries, the total impact of energy R\&D on the global economy may be somewhat smaller. As a result, the sensitivity analysis includes results of simulations using a 2:1 ratio of energy savings to energy R\&D.
} 
since each time period in the ENTICE model represents one decade, I assume that the full effects of price changes on energy R\&D occur within each decade.

Table 1 lists the parameter values used for both the base case simulations, as well as for various alternate scenarios considered in section IV. A complete discussion of the steps required for calibration is available in an appendix.

\section{Policy Simulations}

With the completed ENTICE model in hand, I proceed to simulate the results of imposing a carbon emissions policy on the global economy. The goal in each simulation is to compare the results of imposing a policy under exogenous technological change to the results of imposing a policy under endogenous technological change in the energy sector. I simulate exogenous technological change by restricting energy $R \& D$ to equal the levels found in a base-case no policy simulation. In each, a carbon tax will be used as the policy instrument to achieve reduced emissions. $^{18}$ I calculate the net economic impact of a policy as the present value of consumption under the policy minus the present value of consumption in the base case, in which carbon emissions are uncontrolled. Two policy options are considered: an optimal policy in which the marginal costs of carbon abatement equal the marginal environmental benefits of reduced carbon emissions, and restricting emissions to 1995 levels. The more restrictive policy is included

\footnotetext{
${ }^{18}$ Of course, other policy instruments, such as international permit trading, have received more attention in recent climate negotiations. In a global model such as ENTICE, trading among countries is not possible. Nonetheless, since a successful permit market would equate marginal abatement costs across countries, a carbon tax set at the marginal cost of abatement can also be thought to represent the price of a permit that would result. One difference is that, under permit trading, new innovations would result in cost savings, but not in emissions reductions, since the number of permits is fixed. A discussion of such a simulation follows.
} 
because most climate policies proposed in the policy arena aim for far greater restrictions than called for in an optimizing economic model. ${ }^{19}$

\section{A. Optimal Policy}

Because the DICE model and its variants incorporate environmental damages into the model, it is possible to calculate an optimal carbon policy, in which the marginal costs of carbon abatement equal the marginal benefits of lower emissions. Typically, simulations involving these models find that the optimal policy is to go slow. Since carbon emissions remain in the atmosphere for several hundred years, the marginal damages resulting from any new emissions are modest. Thus, gradually phasing in carbon reduction lowers the opportunity cost of reducing emissions without having much impact on the global climate. As an example, Nordhaus and Boyer (2000) calculate an optimal carbon tax in 2005 of $\$ 9.13$ per ton. In comparison, restricting emissions to 1990 levels would require a carbon tax of $\$ 52.48$.

The first row of table 2 shows the welfare gains for the optimal policy scenario. Including endogenous technological change increases welfare by $8.3 \%$. An optimal carbon tax with exogenous technological change improves welfare by $\$ 1.74$ trillion. This welfare gain increases to $\$ 1.88$ trillion when the effects of $R \& D$ induced by the policy change are considered.

Although the effect of endogenous technological change on overall welfare is significant, its effect on key economic and environmental variables is small. Table 3 provides more detail on the effect of endogenous technological change on key variables. Note that the magnitude of the optimal policy does not change when technology is endogenous. Both the optimal carbon tax

\footnotetext{
${ }^{19}$ For example, the Kyoto Protocol requires industrialized country emissions to be reduced by 5 to 8 percent below 1990 levels. Since the DICE model is global, capturing regional differences, such as the lack of restrictions on developing countries, is not possible. Thus, I use a slightly higher global emissions constraint to allow for higher emissions from developing countries.
} 
and optimal control rate are virtually unchanged. Moreover, although emissions fall somewhat when technological change is endogenous, the slight decrease in emissions has little effect on average global temperature. Figure 2 plots the deviation from 1900 temperature levels with no policy, optimal policy with and without endogenous $R \& D$, and the more restrictive policy limiting emissions to 1995 levels. Even including induced technological change, an optimal carbon policy does not come close to reaching the temperature limits imposed by more restrictive policies. There is almost no variation in global mean temperature between the endogenous and exogenous R\&D case. In fact, after 100 years the temperature is just $0.04 \%$ lower when the role of endogenous technological change is included.

One reason for the small change in atmospheric temperature is that much of the welfare gains from induced technological change come from cost savings that make meeting environmental goals cheaper. To explore this further, I re-ran the model allowing for endogenous energy R\&D and a carbon tax, but fixing emissions in the policy run to equal those found with exogenous $R \& D$ and a carbon tax. In this case, the only benefits coming from increased energy R\&D are potential cost savings, as emissions, and thus climate, do not change from the exogenous R\&D case. ${ }^{20}$ In this case, considering endogenous energy R\&D increases welfare by $8.1 \%$, rather than the $8.3 \%$ increase found when emissions were allowed to change. In the ENTICE model, the primary gains from energy R\&D come not from climate improvements, but from reducing the opportunity cost of reducing fossil fuel emissions.

To help interpret the magnitude of the energy R\&D performed in the simulations, Table 3 includes the level of energy R\&D activity with both exogenous and endogenous R\&D and the

\footnotetext{
${ }^{20}$ This simulation could also be thought of as the effect of using tradable permits, rather than a carbon tax, to implement an "optimal" emissions path.
} 
elasticity of energy R\&D with respect to carbon price. ${ }^{21}$ This figure is calculated for each year based on the difference in both energy $R \& D$ and carbon prices in simulations with and without policy. Based on the results of Popp (2002), the model is calibrated so that this elasticity equals 0.35 in 2005. Because diminishing returns to energy research reduce the inducement effect over time, the elasticity of energy R\&D falls over time, as shown in Figure $3 .^{22}$ Thus, diminishing returns to research have the effect of lowering energy R\&D somewhat in the long-run.

These results present a puzzle. The changes in individual variables are small, yet the welfare gains are more significant. Examining the effect of the carbon tax on energy R\&D helps explain this finding. The additional induced $R \& D$ from the optimal carbon tax is small, as the tax is just a small percentage of the overall price of carbon. ${ }^{23}$ In addition, energy $R \& D$ is just a small part of the overall economy. Because energy R\&D is a small part of the overall economy, and the elasticity of energy $R \& D$ to energy prices is also small, adding induced innovation to the DICE model has little effect on the optimal policy. Nonetheless, because knowledge is cumulative, small changes in R\&D in any given year have important long-run effects.

The finding that technological change has just a small effect on these annual measures emphasizes that it is important to look not at the change in individual variables, but at the overall welfare change. Although the annual value of these benefits may be small, the accumulated value over a 300-year time span is important. The creation of new knowledge not only offers benefits to current generations, but also provides the building blocks for future research. As a result, long-run welfare gains are larger with endogenous technological change. This is

\footnotetext{
${ }^{21}$ Recall that the level of energy $R \& D$ with exogenous technological change is simply the level of energy R\&D from the base case simulation without policy.

${ }^{22}$ To account for the effect of economic growth, all elasticities are calculated using the ratio of energy R\&D to output.

${ }^{23}$ For example, the $\$ 10.16$ in 2005 is just 3.5 percent of the total price of carbon.
} 
illustrated by Figure 4. Figure 4 compares the cumulative welfare gain in the endogenous and exogenous technology cases. ${ }^{24}$ In the years immediately after implementation of a carbon tax, benefits actually accumulate more quickly with exogenous technological change. Early on, the opportunity cost of additional R\&D reduces welfare gains. However, by 2125 , the welfare gains with endogenous technological change begin to outpace those with exogenous technological change, with the difference between them soon stabilizing.

To further illustrate the effects of additional R\&D spending, Figure 5 shows the accumulation of welfare gains over time resulting from an additional $\$ 1$ billion energy R\&D spent in the base year of 1995 . Note that welfare initially falls after the introduction of $\$ 1$ billion of energy R\&D, before reaching an eventual increase of $\$ 5.12$ billion. This $5: 1$ ratio is consistent with the notion that the social returns to R\&D should be significant, due to the public goods nature of research.

\section{B. Restricting Emissions to 1995 Levels}

Adding induced innovation to the ENTICE model also increases welfare in the more restrictive carbon abatement policies, although the effect is smaller. Indeed, the net economic impact of restricting emissions to 1995 levels is negative even with endogenous technological change. Section B of Table 2 presents the net economic impact of these restrictions. Induced innovation improves welfare by $5.6 \%$ under the more restrictive policy, compared to $8.3 \%$ under the optimal policy. As shown in Figure 6, with either endogenous or exogenous energy R\&D, the net economic impact is initially positive, but becomes negative beginning in 2035 . As the restriction becomes more binding, requiring more control, the economic costs become too great

\footnotetext{
${ }^{24}$ That is, the figure shows the net economic impact of the optimal policy through the year given on the $x$-axis.
} 
to justify the policy. For example, in 2025 , the restrictive policy calls for a $29.1 \%$ reduction in emissions, compared to $5.4 \%$ with the optimal policy.

Innovation has a more limited effect under a restrictive policy because increased energy R\&D crowds out other investment. To see this, note that net welfare gain from induced innovation improves from $5.6 \%$ to $8.3 \%$ if no crowding out is assumed. A similar experiment in the optimal policy scenario only increases the welfare gain from $8.3 \%$ to $9.5 \%{ }^{25}$ Stronger emissions restrictions induce more R\&D, which amplifies the welfare effects of crowding out.

Table 3 shows how other variables change when energy $R \& D$ is endogenized. Including induced innovation lowers the carbon tax needed to restrict emissions to 1995 levels by about one percent. Unlike the optimal policy, emissions do not change after induced innovation is included in the model, since this is a command and control policy. Thus, the changes in the carbon tax provide a guideline as to how much tax rates could potentially fall in the optimal scenario if the level of emissions did not change. As before, there is little change in the levels of consumption and output between the endogenous and exogenous cases.

\section{Sensitivity Analysis}

In developing a model such as the ENTICE model, several key assumptions must be made. To calibrate the model, future projections of energy R\&D are based on historical energy R\&D performance. Although these are useful in providing a guide to future energy $R \& D$ performance, there is no guarantee that energy R\&D trends will remain the same. Thus, it is important to consider the potential effects of changes in the behavior of the energy R\&D sector. Furthermore, critical assumptions about the behavior of the R\&D sector, such as the potential role of crowding out, also affect the results. 
In this section, I focus on the sensitivity of the model to key assumptions used to calibrate the model. ${ }^{26}$ I begin by examining three assumptions about the R\&D sector: the opportunity cost of $R \& D$, deviation between the private and social rates of return to $R \& D$, and the decay rate of knowledge. I then examine three key choices made in calibrating the model: the percentage of exogenous R\&D remaining, the elasticity of energy $R \& D$, and the energy savings resulting from such R\&D. For each simulation, changes in the parameters were needed. Table 1 shows the parameter assumptions for each scenario. Table 2 presents the net economic impact of each scenario.

\section{A. The Opportunity Cost of $R \& D$}

The results of section III, along with previous research on induced innovation and climate policy, suggest that the potential for energy R\&D to crowd out other forms of R\&D may limit the gains from induced innovation. Goulder and Schneider (1999) first noted that models ignoring such costs underestimate the costs of carbon policy. I examine this claim more carefully here, and show that assumptions about the opportunity cost of R\&D are crucial in explaining the limiting role of induced technological change found by many recent models.

In the ENTICE model, increases in the opportunity cost of energy R\&D come from potential crowding out of other, more general R\&D. The base model assumes $50 \%$ of energy R\&D comes at the expense of other research opportunities. To examine the importance of this

\footnotetext{
${ }^{25}$ The sensitivity analysis in section IV provides more detail on the effect of crowding out.

${ }^{26}$ Although it is possible to check the sensitivity of the model to the individual R\&D parameters, these results are less meaningful, as the resulting energy R\&D would not be consistent with real-world data. Upon changing one parameter, it is possible to adjust more than one parameter at a time to get other patterns of energy R\&D that closely match the data. In these cases, the results are similar to those presented above. In general, changing any of the $R \& D$ parameters has little effect. The only variable experiencing significant effects is energy $R \& D$, but since energy $R \& D$ is such a small portion of the total economy, other variables are not affected. The one exception is that increasing the elasticity of substitution, $\rho$, increases the elasticity of energy R\&D with respect to price, and thus the level of R\&D induced in each simulation. Sensitivity analysis based on this is presented below. Results of sensitivity analysis for other individual parameters are available from the author by request.
} 
assumption, I consider a low opportunity cost case with no crowding out, and a high opportunity cost case with complete crowding out. In doing so, it is important to note that changing the opportunity cost of R\&D changes the level of energy R\&D. However, the model is designed to be calibrated to actual values of energy R\&D. Thus, I present lower bound and upper bound values for the sensitivity to potential crowding out effects. The upper bound scenario allows R\&D to adjust as a result of changes in the opportunity cost. This, for example, could be thought of as the maximum gains possible from government policy that was able to alleviate potential crowding out effects. ${ }^{27}$ As a lower bound, I run the model changing the opportunity cost of $R \& D$, but constrain energy $R \& D$ in each case to equal energy $R \& D$ in the corresponding base case scenario. Here, for example, welfare gains in the low opportunity cost case should be interpreted as the gains from removing the assumption of partial crowding out. They are not the gains that would result if the government intervened to remedy the problem of partial crowding out.

Beginning with the optimal policy simulations, the upper bound scenarios suggest policies that could alleviate potential crowding out effects would have large impacts. Completely removing crowding out of R\&D increases the welfare gain from induced innovation in the optimal simulation from 8.3 percent to 43.6 percent. Similarly, simulations with complete crowding out lead to just a $1.8 \%$ gain from induced innovation. The more conservative lower bound simulations, which change the opportunity cost of $R \& D$ but constrain energy $R \& D$ to historical levels, also suggest that assumptions about crowding out are important. However, the magnitude of the effect is smaller. Assuming no crowding out increases the welfare gain from induced R\&D from $8.3 \%$ to $9.5 \%$ in the optimal simulation, whereas assuming full crowding out

\footnotetext{
${ }^{27}$ In these simulations, energy R\&D levels change in both the base case and in the policy scenarios. The effect of policy that addressed opportunity costs only in conjunction with a climate policy will fall in between the upper and
} 
lowers the gain from $8.3 \%$ to $7.6 \%$. In the more restrictive emissions policy case, the opportunity cost is more harmful, since more $\mathrm{R} \& \mathrm{D}$ is induced by the policy change. Thus, as discussed before, changes in the opportunity cost have a greater impact on net economic welfare than with the optimal policy.

These results suggest that assumptions about the opportunity cost of $\mathrm{R} \& \mathrm{D}$ are a key difference among models. For example, Nordhaus (2002) assumes complete crowding out of R\&D, which limits the potential welfare gains from his model. In comparison, models such as Buonanno et al. (2003) that do not include crowding out are more optimistic about the possible effects of induced technological change. More importantly, this suggests that models using learning-by-doing as the avenue for technological improvement will overstate the potential of technological change, as such crowding out does not occur in learning by doing models. Although such models have an opportunity cost to increasing investment in alternative energy technologies, this cost is simply the loss of one dollar of potential investment elsewhere, as opposed to the loss of more productive R\&D funds from elsewhere in the economy. For example, both Gerlagh and van der Zwaan (2003) and Manne and Richels (2002) use learning by doing to model technological change, and both find welfare gains from technology to be significantly higher than in ENTICE. ${ }^{28}$

\section{B. Deviation Between the Private and Social Rate of Return}

The base model constrains the social rate of return on R\&D to be four times greater than that of the return on other investment. This assumption is consistent with the empirical finding that firms underinvest in research, as they are unable to capture the entire social returns.

lower bounds. 
However, the problem of underinvestment could be addressed by subsidies to energy R\&D, if government investments in R\&D are set so that all social returns are captured. Models that do not include market failures, such as Buonanno et al. (2003) implicitly assume that government R\&D subsidies are sufficient to correct all market failures.

Simulations removing the constraint on returns to R\&D suggest that the returns on such subsidies could be quite significant. The gain from ETC for the optimal policy improves to $14.0 \%$ when energy subsidies are considered. Only the upper bound of the low opportunity cost scenario has a higher welfare gain. Similarly, adding R\&D subsidies to the endogenous R\&D case increases the net welfare gain to seven percent in the more restrictive policy case.

\section{Decay Rate}

Many models of R\&D assume that the stock of accumulated knowledge decays over time, due to obsolescence. The base model assumes no such decay, as such an assumption is necessary for the base (no policy) run to accurately simulate both energy R\&D and emissions levels. Here, I evaluate the effect of knowledge decay by assuming a ten-percent decay of knowledge. I consider two possible scenarios. In the first scenario, base emissions are calibrated correctly, but long-run energy R\&D levels are higher than justified by historical standards. This is because some energy R\&D now serves the purpose of simply replacing decayed knowledge, rather than providing new energy savings. I calibrate the second scenario so that energy R\&D levels are consistent with historical levels. Since there is not enough R\&D to replace decayed knowledge in this instance, the resulting long-run emissions are higher than the base model. ${ }^{29}$ Not surprisingly, adding decay decreases the welfare gains from induced innovation, although

\footnotetext{
${ }^{28}$ Gerlagh and van der Zwaan (2003) report that welfare improves by a factor of three when learning-by-doing is included. Manne and Richels find that cost fall from 42-72 percent when learning-by-doing is considered.
} 
the effect is not large. In the first scenario, the welfare gain from endogenous energy R\&D falls from $8.3 \%$ to $7.1 \%$. The effect of knowledge decay is more noticeable in the second scenario, in which the welfare gain is only $4.4 \%$. Similar results are found with the more restrictive emissions policy.

\section{Return to energy $R \& D$}

The previous three subsections include sensitivity about assumptions made for modeling the R\&D sector. The remaining three subsections address sensitivity to the values used to calibrate the model. Although these values are based on historical energy R\&D performance, there is no guarantee that energy $R \& D$ trends will remain the same. Understanding the potential effects of changes in these values is crucial. The simulations suggest that assumptions about the potential savings from energy R\&D are most important.

Following Popp (2001), in the base model I assume each dollar of energy R\&D leads to $\$ 4$ of energy savings. Here, I re-calibrate the model assuming that each dollar of energy savings leads to only $\$ 2$ of energy savings. As would be expected, reducing potential energy savings in half reduces the potential welfare gains from induced innovation by approximately one-half. Welfare increases only $4.3 \%$ when energy $R \& D$ is endogenous, compared to $8.3 \%$ in the base case. Similarly, the welfare increase falls from $5.6 \%$ to $3.7 \%$ under the more restrictive emissions policy. Thus, uncertainty about the potential savings resulting from future energy $\mathrm{R} \& \mathrm{D}$ is an important consideration. Unfortunately, most simulations to not report the energy savings that occur per dollar of R\&D spending, so evaluation of other models on this important assumption is not possible. ${ }^{30}$

\footnotetext{
${ }^{29}$ Figures showing the resulting emissions and energy R\&D levels are available from the author by request.

${ }^{30}$ The one exception is Nordhaus (2002).
} 


\section{E. Elasticity of $R \& D$}

The base model is calibrated so that this elasticity equals 0.35 in 2005 , and declines over time. This is consistent with the results of Popp (2002). In this section, I re-calibrate the model to yield elasticities approximately twice as high as those of the base case. Figure 3 shows the elasticities in the base case and alternative scenario. Interestingly, doubling the response of R\&D does not have a large impact on welfare. Under an optimal carbon policy, the welfare gains from induced innovation increase by just $6 \%$, from $8.3 \%$ to $8.8 \%$. One reason for the small effect is that some of the gains are canceled by potential crowding out. When the assumption of partial crowding out is removed, welfare gains rise by $33 \%$, from $9.5 \%$ to $12.7 \%$.

Under a more restrictive carbon policy, changes in the elasticity appear more important. Here, adding induced energy R\&D increases welfare by $14.4 \%$, compared to $5.5 \%$ in the base case. Because the costs of a restrictive policy are much greater, a higher elasticity of energy R\&D with respect to energy prices leads to a significant increase in $R \& D$ under the restrictive policy. Unfortunately, most other models do not report the elasticities resulting from parameter choices, making evaluation of other models on this feature difficult.

\section{F. Exogenous Reduction of Carbon Intensity}

One potential concern is that, in order to maintain realistic projections for baseline emissions, much of the exogenous reduction of carbon intensity described in section II remains in the model with endogenous R\&D. This assumption is necessary for the base (no policy) model to accurately simulate both the energy R\&D sector and projected carbon emissions. It does not, however, affect the potential welfare gains from induced innovation. As Figure 7 shows, lowering this percentage leads to significantly higher levels of long run emissions. However, what matters for the welfare gains is not the baseline level of emissions, but rather the 
changes that occur when policy is enacted, both with and without endogenous technological change. Since the level of induced R\&D does not change much, the welfare gains from endogenous R\&D are similar to the previous results, with a net economic impact of $7.1 \%{ }^{31}$

\section{Discussion}

These results suggest that omitting induced innovation from the DICE model overstates the costs of complying with carbon change policies. Using the base parameters, welfare under an optimal carbon tax improves by $8.3 \%$ when induced innovation is considered. Furthermore, the model allows for straightforward testing of key assumptions about knowledge markets. Most important is the finding that removing crowding out may lead to large increases in welfare. This calls into question the results of models such as Buonanno et al. (2003), that not only do not have crowding out of R\&D, but allow for complementarities between energy R\&D and other forms of R\&D. In addition, it suggests that modeling technological change solely by learning by doing overstates the potential of new technologies to lower cost. ${ }^{32}$

In addition, assumptions about market failures in knowledge markets are important. When R\&D is left to the private sector, the inability to completely appropriate returns will lead to underinvestment. Removing the deviation between private and social rates of return in the model increases the net welfare gain to $14 \%$. Thus, models that neglect to include some notion of $R \& D$ market failure will provide more optimistic results. While such results are attainable, it is important to note that R\&D subsidies from government would typically be needed for that to occur.

${ }^{31}$ Alternatively, one can calibrate the model so that emissions fit the desired pattern by having R\&D rise substantially to adjust for the lack of exogenous technological change. This leads to a more significant increase in welfare, but also very unrealistic R\&D levels. For example, energy R\&D is 300\% higher in 2005 in this simulation. 
The results of this paper suggest several important lessons for policymakers tempted to rely on technology as a cure-all for climate change. First, and most obvious, is that these technological gains will not occur without some policy signal to innovators that energy efficiency research will be profitable. Second, although induced innovation can lower the cost of any climate change strategy, the effect on the environment was minimal. Most of the welfare gains from induced innovation in the optimal policy scenario came from cost savings, not temperature reductions. Achieving significant reductions in future warming will not be possible without restrictive climate change policies. As the simulations restricting emissions to 1995 levels show, these are likely to come at a cost to society, even when the potential of induced innovation is realized.

Third, as other researchers have also noted (see, for example, Goulder and Schneider 1999), new energy research comes at a cost, as other investments are reduced. In particular, any reductions in other $R \& D$ will limit the welfare gains from new energy $R \& D$. As shown in the sensitivity analysis, going from complete crowding out of other R\&D to no crowding out of other R\&D increases the potential welfare gains from induced innovation by as much as a factor of five. More research on both the magnitude of any crowding out that may occur, as well as policies that could help alleviate crowding out, would both be helpful.

Fourth, the limiting effect of market failures in R\&D markets suggest that R\&D subsidies and government financed $R \& D$ could improve the potential gains from new technologies. In deciding on government R\&D projects, policymakers can focus on the social, rather than private rates of return. As shown in the sensitivity analysis, doing so could increase the potential gains from induced technology by nearly two-thirds.

\footnotetext{
${ }^{32}$ This is not to say that learning-by-doing is not important. Rather, it is that learning-by-doing should not be modeled as the only way in which technology evolves.
} 
Finally, limitations of the ENTICE model must be discussed. First, by modeling the world as a single region, the ENTICE model simplifies policy dramatically. Expanding these results to a regional model, based on Nordhaus' RICE model, would be beneficial. However, to do so would require research on how innovative effects vary by region, and how technology diffuses across regions. In general, new innovations are developed in the industrialized world and diffuse slowly to developing countries. For example, of the $\$ 500$ billion spent on $R \& D$ in the 28 OECD countries in 1997, 85\% occurred in just 7 countries (National Science Board, 2000).

Second, the ENTICE model only includes innovation designed to improve energy efficiency. Yet, one of the most important long-term research goals is providing alternative fuels that provide an emissions-free energy alternative. Policies such as a carbon tax are likely to induce R\&D aimed at substitutes for fossil fuels, such as solar energy. In fact, the energy crisis of the 1970s led to a dramatic increase in R\&D for alternative fuels. By speeding the invention of a non-carbon based backstop technology, induced innovation may have a more significant effect than is found in the ENTICE model. ${ }^{33}$ Adding such backstop technologies to the model is another important step for future research.

Third, the ENTICE model does not include uncertainty. Not only are the future returns to R\&D uncertain, but the potential impact of climate change itself is also uncertain. Uncertainty may produce an option value for increased $R \& D$, which could provide a cushion should the climate problem turn out to be more severe than anticipated. Adding endogenous technological change to a model allowing for uncertain climate effects, such as Nordhaus and Popp (1997), would be a useful extension.

\footnotetext{
${ }^{33}$ Gerlagh (2002) presents a theoretical demonstration of the potential of backstop technologies.
} 


\section{References}

Ahmad, Syed (1966), "On the Theory of Induced Innovation,” Economic Journal, 76(302), 34457.

Binswanger, Hans P. (1974), “A Microeconomic Approach to Innovation," Economic Journal, 84(336), 940-58.

Buonanno, Paolo, Carlo Carraro, and Marzio Galeotti (2003), "Endogenous Induced Technical Change and the Costs of Kyoto," Resource and Energy Economics, 25(1), 11-34.

Chakravorty, Ujjayant, James Roumasset, and Kinping Tse (1997), "Endogenous Substitution among Energy Resources and Global Warming, Journal of Political Economy, 105, 1201-1234.

Fisher, Carolyn, Ian W. H. Parry, William A. Pizer (1998), "Instrument Choice for Environmental Protection When Environmental Protection is Endogenous," Resources for the Future Discussion Paper 99-04.

Gerlagh, Reyer (2002), "Induced Technological Change Under Technology Competition," Institute for Environmental Studies Working Paper D02-01, Vrije Universiteit, Amsterdam.

Gerlagh, Reyer and Bob van der Zwaan (2003), "Gross World Product and Consumption in a Global Warming Model with Endogenous Technological Change," Resource and Energy Economics, 25(1), 35-57.

Goulder, Lawrence H. and Stephen H. Schneider (1999), "Induced Technological Change and the Attractivenes of $\mathrm{CO}_{2}$ Emissions Abatement," Resource and Energy Economics, 21, 211-253.

Goulder, Lawrence H. and Koshy Mathai (2000), "Optimal CO2 Abatement in the Presence of Induced Technological Change," Journal of Environmental Economics and Management, 39(1), 1-38.

Griliches, Zvi (1995), "R\&D and Productivity: Econometric Results and Measurement Issues," in Handbook of the Economics of Innovation and Technological Change, Paul Stoneman, ed., Blackwell Publishers, Cambridge, MA.

Griliches, Zvi (1989), "Patents: Recent Trends and Puzzles," Brookings Papers on Economic Activity: Microeconomics, pp. 291-330.

Grübler, Arnulf and Sabine Messner (1998), "Technological Change and the Timing of Mitigation Measures," Energy Economics, 20(5-6), 495-512.

Hall, Bronwyn (1995), "The Private and Social Returns to Research and Development," in Technology, R\&D, and the Economy, Bruce Smith and Claude Barfield, eds., Brookings, 140-183. 
Hicks, John R. (1932), The Theory of Wages, London: Macmillan.

Jaffe, Adam B. (1986), "Technological Opportunity and Spillover of R\&D: Evidence from Firms’ Patents, Profits, and Market Value,” American Economic Review, 76, 984-1001.

Jaffe, Adam B., Richard G. Newell, and Robert N. Stavins (2003), “Technological Change and the Environment," forthcoming in Handbook of Environmental Economics, K.G. Mäler \& J. Vincent (Eds.), North Holland, Amsterdam.

Jaffe, Adam B. and Karen Palmer (1997), "Environmental Regulation and Innovation: A Panel Data Study," Review of Economics and Statistics, 79, 610-619.

Jones, Charles (1995), "R\&D Based Models of Economic Growth," Journal of Political Economy, 103, 739-784.

Kamien, Morton I. and Schwartz, Nancy L. (1968), “Optimal Induced Technical Change," Econometrica, 36(1), 1-17.

Lanjouw, Jean O. and Ashoka Mody (1996), "Innovation and the International Diffusion of Environmentally Responsive Technology," Research Policy, 25, 549-571.

Magat, Wesley A. (1978), "Pollution Control and Technological Advance: A Dynamic Model of the Firm," Journal of Environmental Economics and Management, 5, 1-25.

Manne, Alan S. and Richard G. Richels (2002), "The Impact of Learning-By-Doing on the Timing and Costs of $\mathrm{CO}_{2}$ Abatement," AEI-Brookings Joint Center for Regulatory Studies Working Paper 02-8.

Mansfield, Edwin (1996), "Microeconomic Policy and Technological Change," in Technology and Growth: Conference Proceedings, Jeffrey C. Fuhrer and Jane Sneddon Little, eds., Federal Reserve Bank of Boston, 183-200.

Mansfield, Edwin (1977), "Social and Private Rates of Return from Industrial Innovations," Quarterly Journal of Economics, 91, 221-240.

Messner, Sabine (1997), "Endogenized Technological Learning in an Energy Systems Model," Journal of Evolutionary Economics, 7(3), 291-313.

Milliman, Scott R. and Raymond Prince (1989), "Firm Incentives to Promote Technological Change in Pollution Control," Journal of Environmental Economics and Management, $17,247-165$.

National Science Board (2000), Science and Engineering Indicators - 2000, National Science Foundation, Arlington, VA (NSB-00-1).

Newell, Richard G., Adam B. Jaffe, and Robert N. Stavins (1999), "The Induced Innovation Hypothesis and Energy-Saving Technological Change," Quarterly Journal of Economics, $114,941-975$. 
Nordhaus, William (1999), "Modeling Induced Innovation in Climate-Change Policy," mimeo, Yale University.

Nordhaus, William (1994), Managing the Global Commons: The Economics of the Greenhouse Effect, MIT Press, Cambridge, MA.

Nordhaus, William and Joseph Boyer (2000), Warming the World: Economic Models of Global Warming, MIT Press, Cambridge, MA.

Nordhaus, William and David Popp (1997), "What is the Value of Scientific Knowledge? An Application to Global Warming Using the PRICE Model", The Energy Journal, 18(1), 145.

Pakes, Ariel (1985), “On Patents, R\&D, and the Stock Market Rate of Return," Journal of Political Economy, 93, 390-409.

Parry, Ian W.H. (1995), “Optimal Pollution Taxes and Endogenous Technological Progress," Resource and Energy Economics, 17(1), 69-85.

Popp, David (2002) “Induced Innovation and Energy Prices,” American Economic Review, 92, 160-180.

Popp, David (2001) "The Effect of New Technology on Energy Consumption," Resource and Energy Economics, 23, 215-239.

Popp, David (1998), “The Productivity of Energy Research,” University of Kansas Working Paper \#1998-4.

Popp, David (1997), Induced Innovation, Energy Prices, and the Environment, Ph.D. dissertation, Yale University.

Porter, Michael E. and Scott Stern (2000), "Measuring the 'Ideas' Production Function: Evidence From International Patent Output,” NBER Working Paper \#7891.

Portney, Paul R. and John P. Weyant eds. (1999), Discounting and Intergenerational Equity, Resources for the Future, Washington, D.C.

Romer, Paul M. (1990), “Endogenous Technological Change,” Journal of Political Economy, 98, S71-S102. 
Figure 1-Spending on Energy and Non-energy R\&D by U.S. Industries

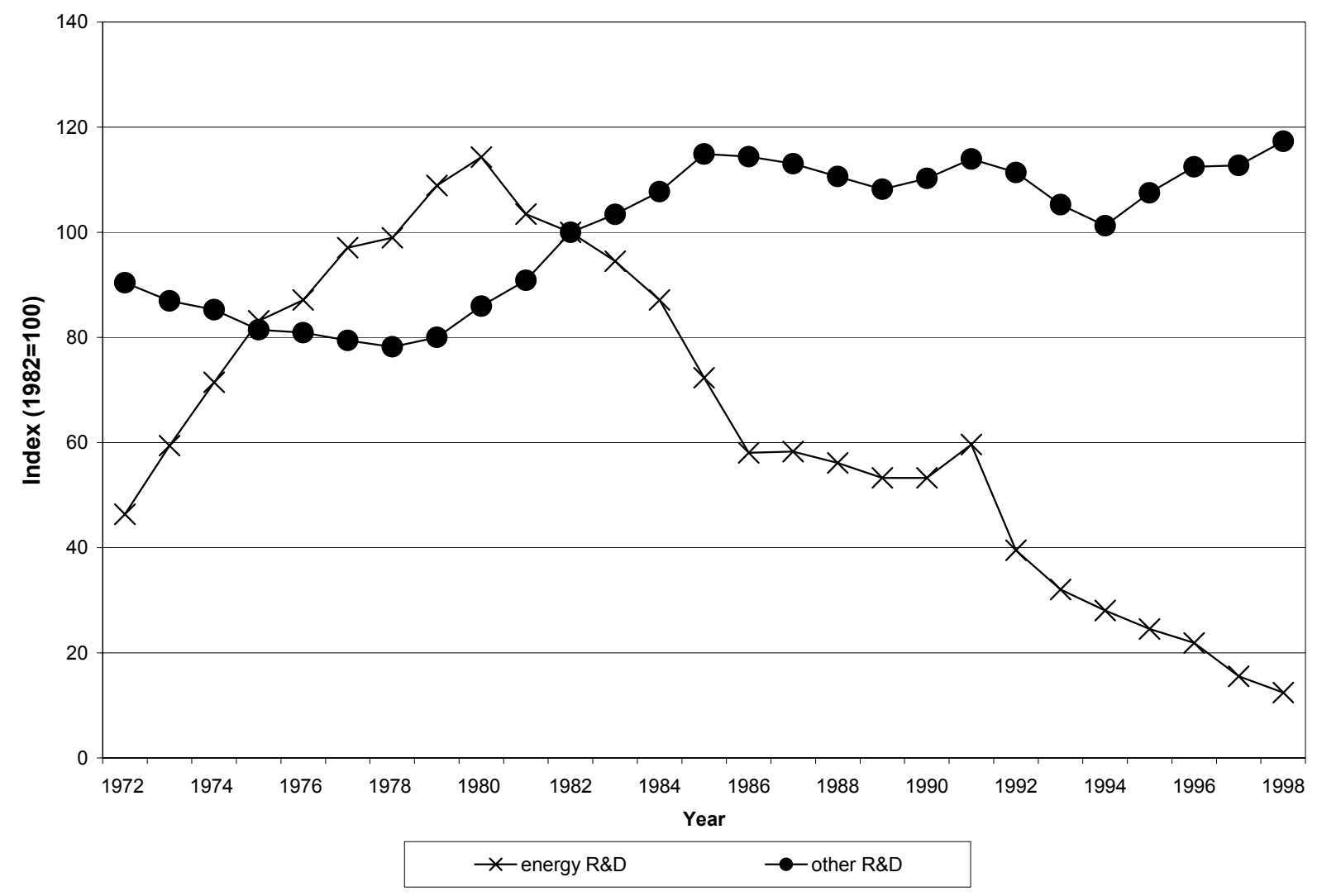




\section{Figure 2 - Mean Global Temperature}

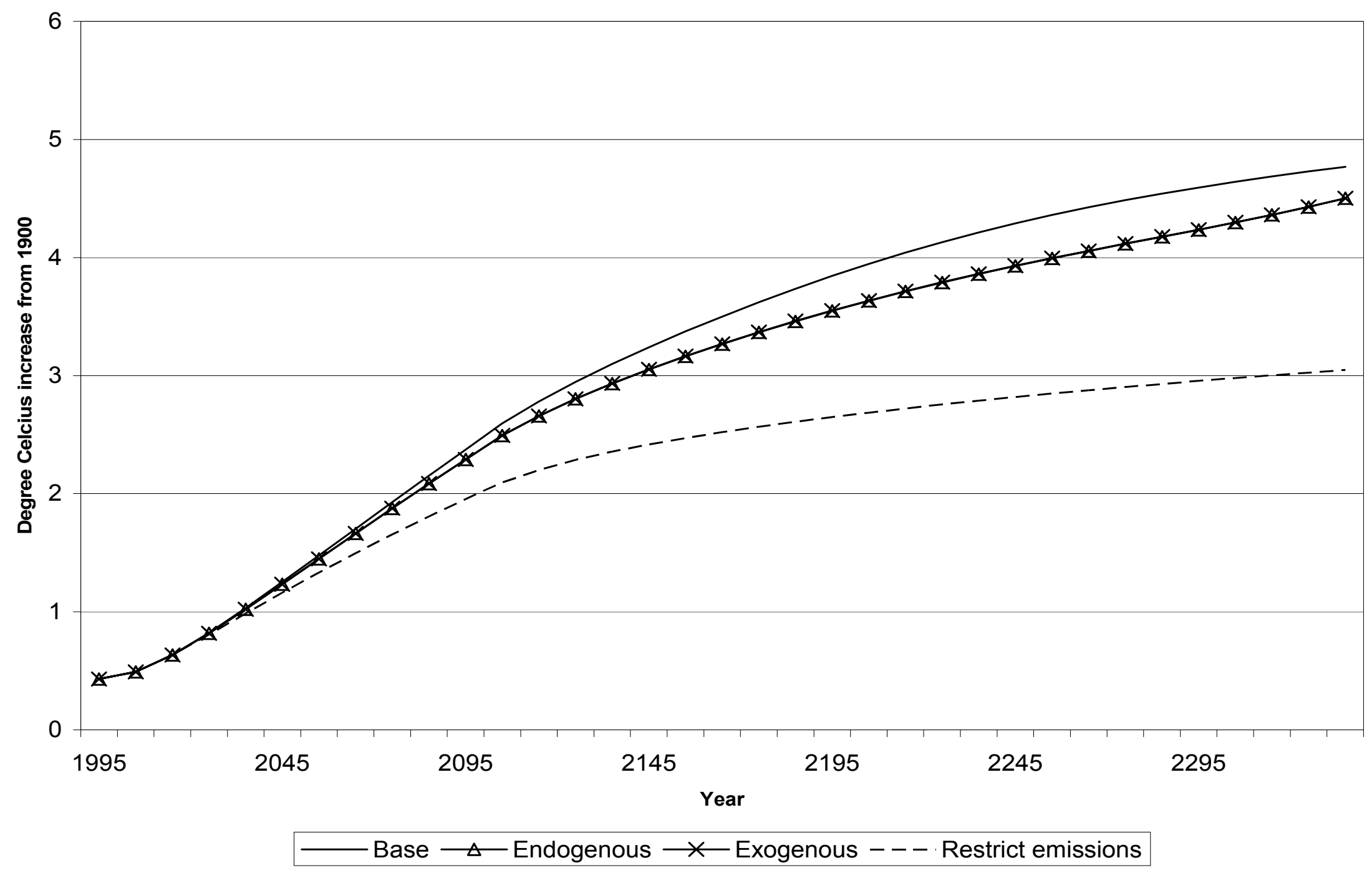

The figure shows the departure of mean global temperature from 1990 levels, reported in degrees Celsius. Note that induced energy R\&D has little effect on temperature. 
Figure 3 - Elasticity of Energy R\&D

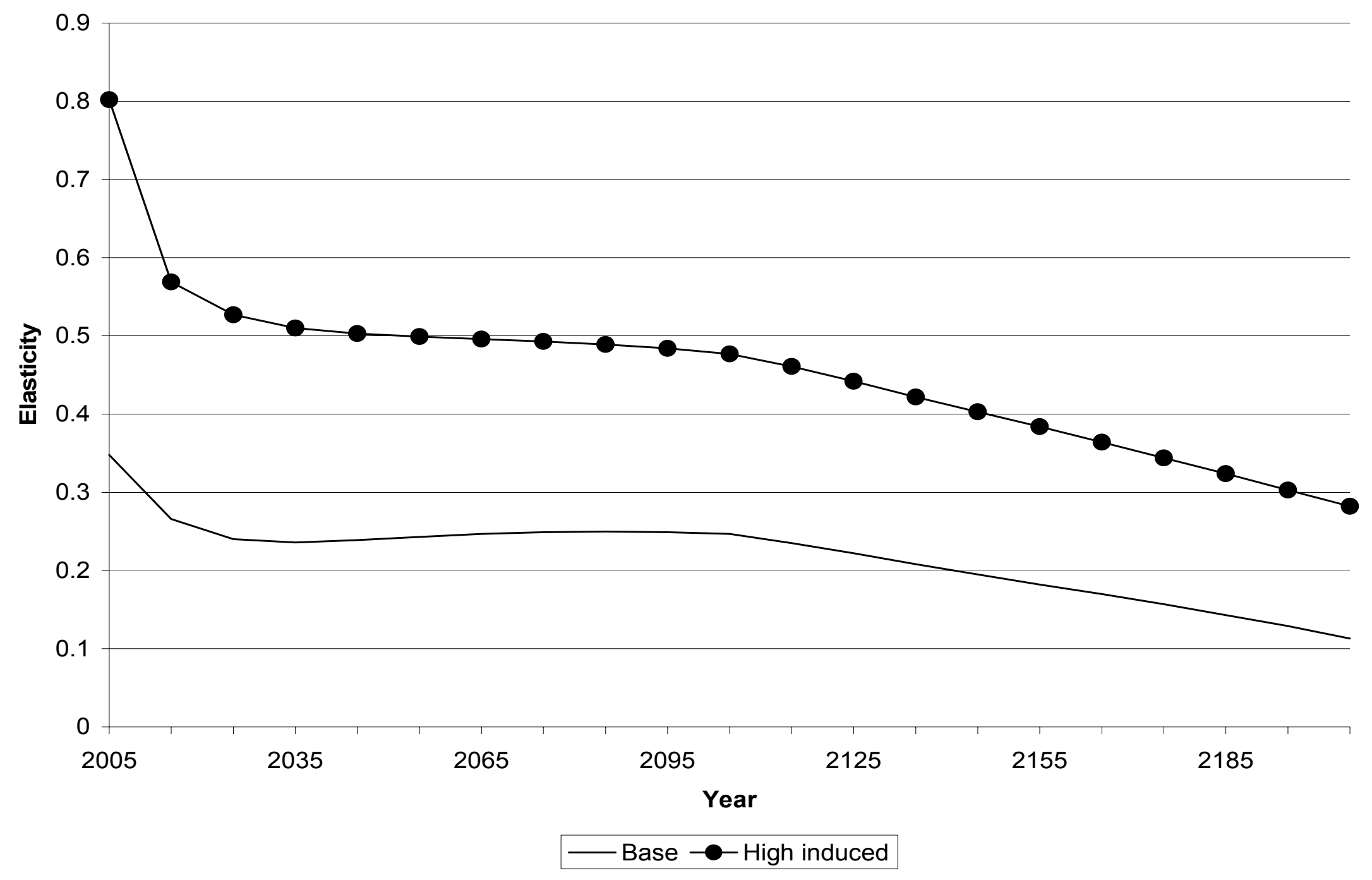

The figure shows the elasticity of energy R\&D to energy prices between the base case and optimal policy simulation. The base case presents the elasticity assumed in the base run presented in section III. A simulation using the elasticity from the high induced case is presented in section IV 
Figure 4 - Welfare Gains Over Time-Optimal Policy

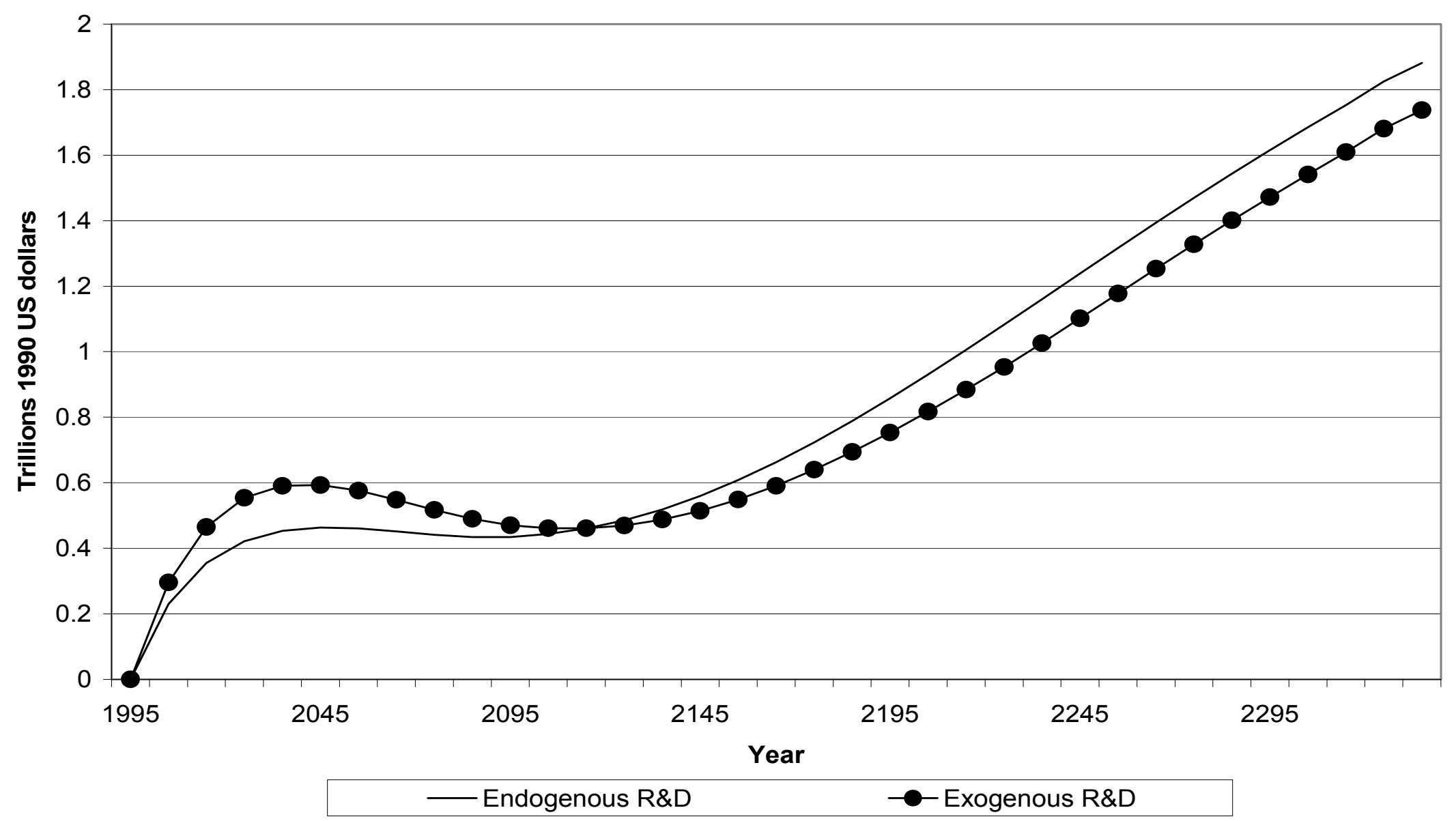

The figure shows the cumulative gains in welfare from an optimal carbon tax. Note that welfare in the induced innovation is initially lower than exogenous R\&D, but that induced innovation leads to larger long run improvements than in a simulation with exogenous technological change. 


\section{Figure 5 - Welfare Effects of Marginal Energy R\&D}

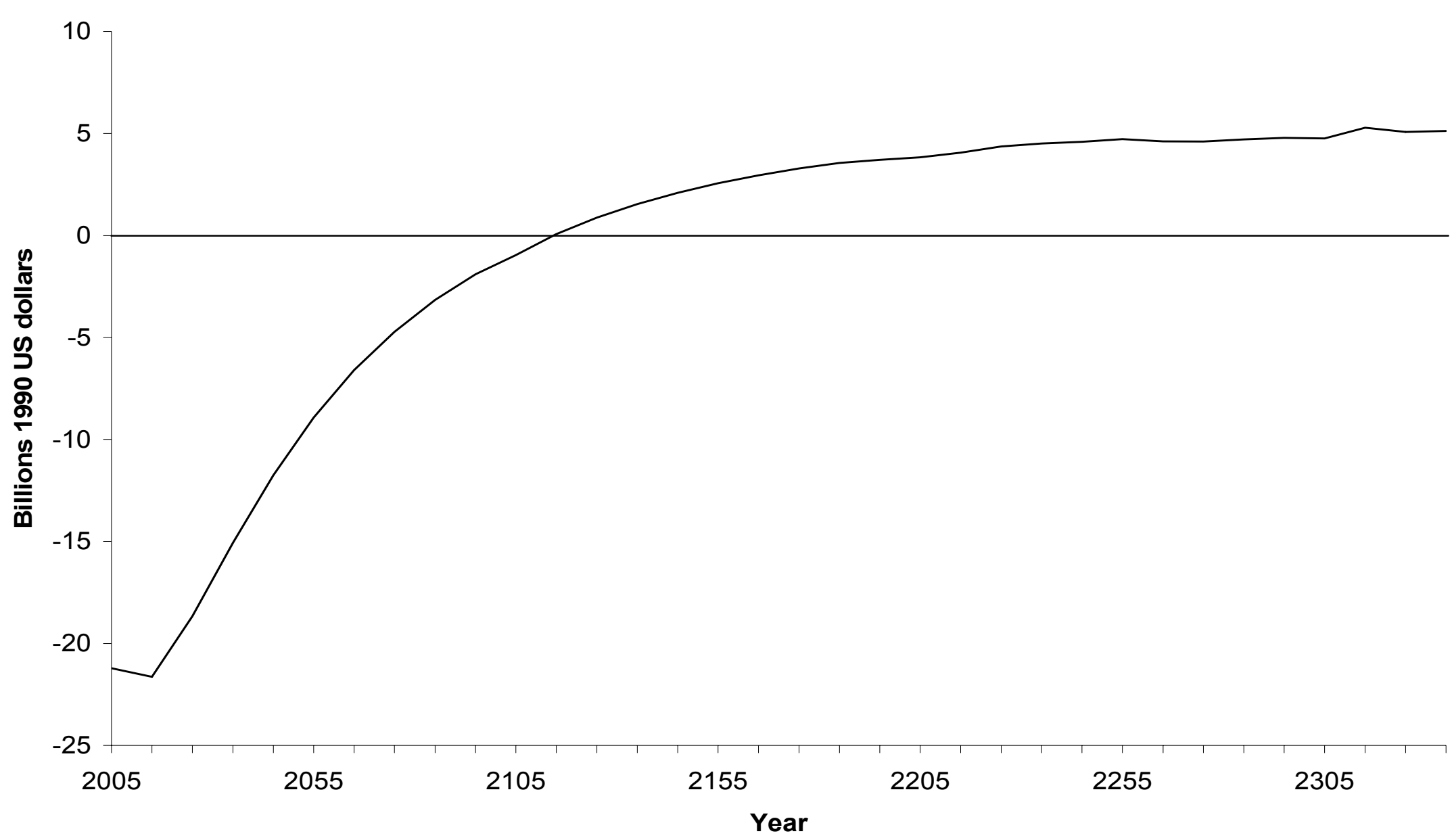

The figure shows the welfare effects of an additional $\$ 1$ billion of energy R\&D spent in 1995. The initial effects are negative, as the immediate environmental benefits do not justify the opportunity cost of additional energy R\&D. However, by also enhancing the productivity of future $R \& D$, the cumulative effect of marginal energy $R \& D$ is positive. 
Figure 6 - Welfare Gains Over Time—Restrict Emissions to 1995 levels

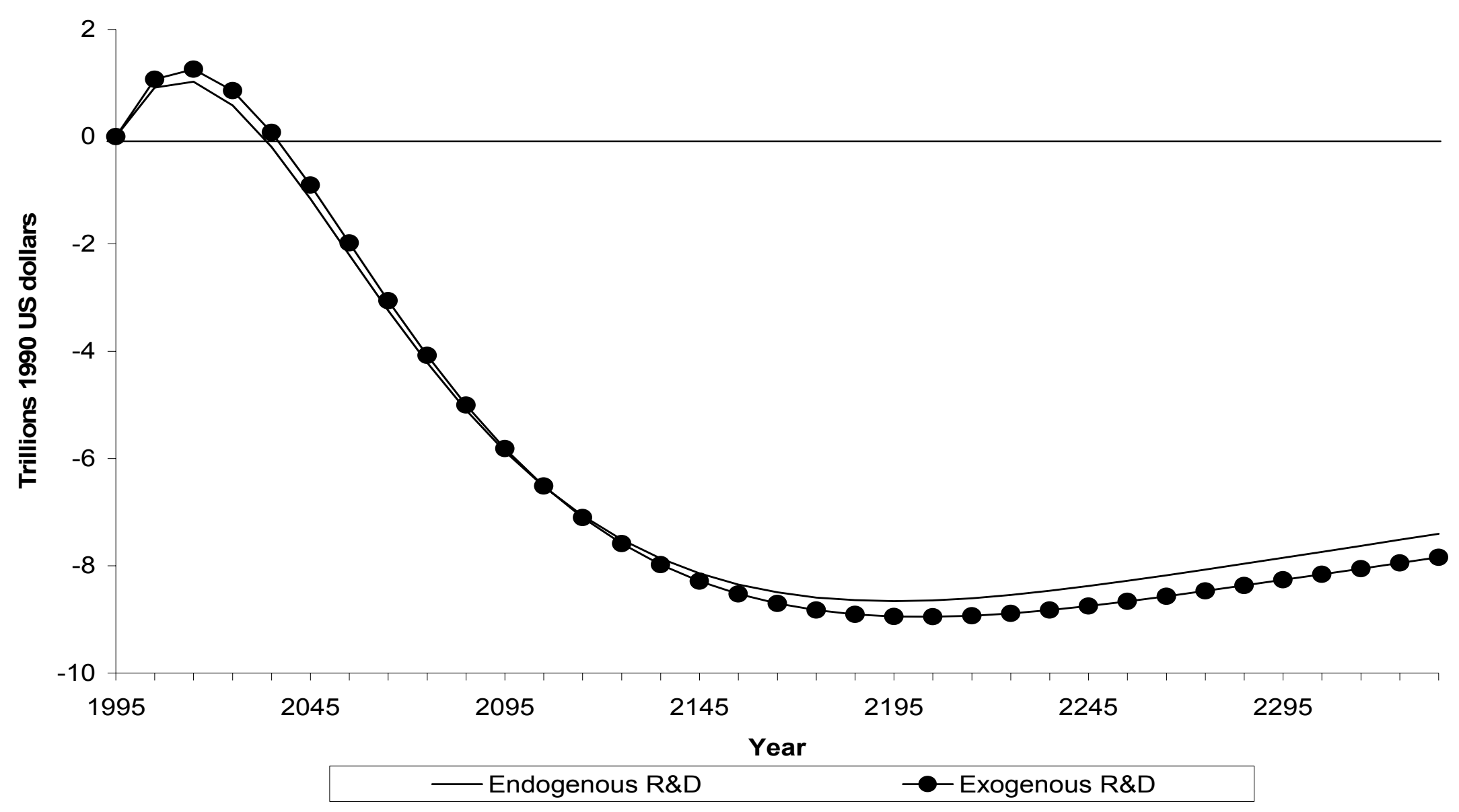

The figure shows the cumulative gains in welfare from restricting emissions to 1995 levels. Note that the net economic effects are initially positive, but as greater reductions are required in future years, the long-run net economic impact is negative. 
Figure 7 - Emissions Over Time - Sensitivity to Exogenous Reductions in Carbon Intensity

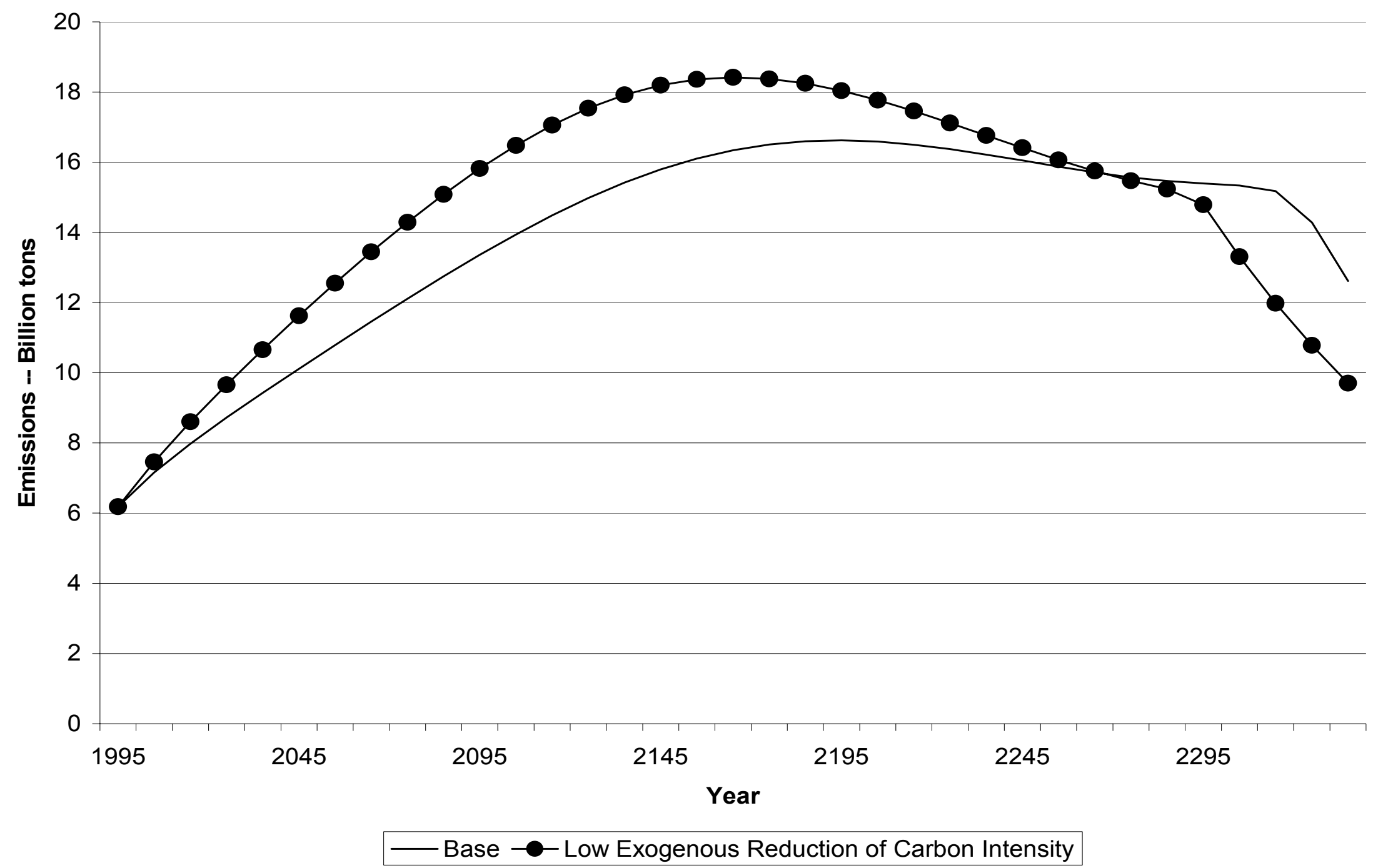

The figure shows how base case emissions increase when the percentage of exogenous reductions in carbon intensity is reduced. 
Table 1 - Summary of Parameter Values

\begin{tabular}{|c|c|c|c|c|c|c|c|c|c|}
\hline & $\begin{array}{l}\text { scaling } \\
\text { factor } \\
\left(\alpha_{H}\right)\end{array}$ & $\begin{array}{c}\text { initial } \\
\text { energy } \\
\text { human } \\
\text { capital } \\
\left(H E_{0}\right)\end{array}$ & IPF: a & IPF: $b$ & IPF: $\phi$ & $\begin{array}{c}\text { substitution } \\
\text { parameter } \\
(\rho)\end{array}$ & $\begin{array}{c}\text { percentage } \\
\text { exog. } \\
\text { carbon } \\
\text { intensity } \\
\text { reduction } \\
\left(\alpha_{\Phi}\right)\end{array}$ & $\begin{array}{c}\text { decay of } \\
\text { knowledge } \\
\left(\delta_{H}\right)\end{array}$ & $\begin{array}{l}\text { crowding } \\
\text { out of } \\
\text { general } \\
\text { R\&D }\end{array}$ \\
\hline Base parameters & 0.944 & 0.0001 & 0.02202 & 0.18 & 0.53 & 0.41 & 0.8 & 0 & 0.5 \\
\hline Low opportunity cost & 0.944 & 0.0001 & 0.02202 & 0.18 & 0.53 & 0.41 & 0.8 & 0 & 0 \\
\hline High opportunity cost & 0.944 & 0.0001 & 0.02202 & 0.18 & 0.53 & 0.41 & 0.8 & 0 & 1 \\
\hline Decay: High R\&D, base emis. & 1.7 & 0.0001 & 0.0315 & 0.19 & 0.53 & 0.41 & 0.8 & 0.1 & 0.5 \\
\hline Decay: Base R\&D, high emis. & 1.8 & 0.0001 & 0.00785 & 0.3 & 0.4 & 0.363 & 0.8 & 0.1 & 0.5 \\
\hline Low energy savings & 0.876 & 0.0001 & 0.016 & 0.21 & 0.538 & 0.38 & 0.8 & 0 & 0.5 \\
\hline High R\&D elasticity & 0.799 & 0.0001 & 0.0594 & 0.17 & 0.296 & 0.7 & 0.8 & 0 & 0.5 \\
\hline Low exog. carbon intens. & 0.93 & 0.0001 & 0.0218 & 0.18 & 0.53 & 0.41 & 0.5 & 0 & 0.5 \\
\hline
\end{tabular}

The table presents parameter values for both the base ENTICE model presented in section III and for various sensitivity analyses presented in section IV. 


\section{Table 2 - Summary of Net Economic Impacts}

\begin{tabular}{|c|c|c|c|}
\hline A. Optimal Carbon Tax Policy & Endogenous & Exogenous & $\begin{array}{l}\text { Gain from } \\
\text { ETC }\end{array}$ \\
\hline Base model & 1.88 & 1.74 & $8.3 \%$ \\
\hline \multicolumn{4}{|l|}{ Opportunity Cost of R\&D } \\
\hline Low opportunity cost: upper bound & 1.89 & 1.32 & $43.6 \%$ \\
\hline Low opportunity cost: lower bound & 1.91 & 1.75 & $9.5 \%$ \\
\hline High opportunity cost: upper bound & 1.88 & 1.84 & $2.1 \%$ \\
\hline High opportunity cost: lower bound & 1.85 & 1.72 & $7.6 \%$ \\
\hline$R \& D$ Subsidies & 1.98 & 1.74 & $14.0 \%$ \\
\hline \multicolumn{4}{|l|}{ Sensitivity to Decay Rate } \\
\hline High R\&D, base emissions & 1.82 & 1.70 & $7.1 \%$ \\
\hline Base R\&D, high emissions & 1.80 & 1.73 & $4.4 \%$ \\
\hline Low Energy Savings & 1.87 & 1.78 & $4.8 \%$ \\
\hline Elasticity of $R \& D$ & 1.92 & 1.76 & $8.8 \%$ \\
\hline Exogenous Reduction of Carbon Intensity & 2.20 & 2.06 & $7.1 \%$ \\
\hline \multicolumn{4}{|l|}{ B. Restrict Emissions to 1995 Levels } \\
\hline & & & Gain from \\
\hline & Endogenous & Exogenous & ETC \\
\hline Base model & -7.40 & -7.84 & $5.6 \%$ \\
\hline \multicolumn{4}{|l|}{ Opportunity Cost of R\&D } \\
\hline Low opportunity cost: upper bound & -7.17 & -8.24 & $13.0 \%$ \\
\hline Low opportunity cost: lower bound & -7.19 & -7.83 & $8.2 \%$ \\
\hline High opportunity cost: upper bound & -7.68 & -8.00 & $4.0 \%$ \\
\hline High opportunity cost: lower bound & -7.65 & -7.86 & $2.7 \%$ \\
\hline$R \& D$ Subsidies & -7.29 & -7.62 & $4.4 \%$ \\
\hline \multicolumn{4}{|l|}{ Sensitivity to Decay Rate } \\
\hline High R\&D, base emissions & -9.08 & -9.43 & $3.7 \%$ \\
\hline Base R\&D, high emissions & -10.70 & -10.93 & $2.1 \%$ \\
\hline Low Energy Savings & -8.59 & -8.92 & $3.7 \%$ \\
\hline Elasticity of $R \& D$ & -4.06 & -4.74 & $14.4 \%$ \\
\hline Exogenous Reduction of Carbon Intensity & -11.16 & -11.68 & $4.5 \%$ \\
\hline
\end{tabular}

Note: all figures in trillions of 1990 US dollars.

The table shows the net economic impact, measured by the difference in the present value of consumption between the policy and a no policy simulation, for various model scenarios. The table shows the net economic impact with both endogenous and exogenous energy R\&D, as well as the increase in welfare resulting from endogenizing energy R\&D. Base case results are presented in section III, and the remaining trials are presented in the sensitivity analysis of section IV. The top half of the table shows the net economic impact for an optimal carbon policy, and the bottom half shows the impact for a policy restricting emissions to 1995 levels. 


\section{Table 3 - Key Variables - Optimal Policy}

\begin{tabular}{|c|c|c|c|c|c|c|c|}
\hline & 1995 & 2005 & 2015 & 2025 & 2055 & 2105 & 2205 \\
\hline \multicolumn{8}{|l|}{ Carbon Tax (\$/ton) } \\
\hline Endogenous R\&D & $\mathrm{N} / \mathrm{A}$ & $\$ 10.16$ & $\$ 14.57$ & $\$ 19.48$ & $\$ 36.81$ & $\$ 70.17$ & $\$ 142.16$ \\
\hline Exogenous R\&D & $\mathrm{N} / \mathrm{A}$ & $\$ 10.17$ & $\$ 14.57$ & $\$ 19.49$ & $\$ 36.82$ & $\$ 70.16$ & $\$ 142.04$ \\
\hline$\% \Delta$ Endog. vs. Exog. & & $-0.10 \%$ & $0.00 \%$ & $-0.05 \%$ & $-0.03 \%$ & $0.01 \%$ & $0.08 \%$ \\
\hline \multicolumn{8}{|c|}{ Energy R\&D -- billions 1990 US dollars } \\
\hline Endogenous R\&D & 10.00 & 13.34 & 17.16 & 20.21 & 27.66 & 40.41 & 75.44 \\
\hline Exogenous R\&D & 10.00 & 13.14 & 16.90 & 19.86 & 26.91 & 38.93 & 76.05 \\
\hline Elasticity & $\mathrm{N} / \mathrm{A}$ & 0.35 & 0.27 & 0.24 & 0.25 & 0.26 & 0.11 \\
\hline \multicolumn{8}{|l|}{ Emissions -- billion tons } \\
\hline No Policy & 6.187 & 7.157 & 7.982 & 8.722 & 10.791 & 13.943 & 16.589 \\
\hline Endogenous R\&D & 6.187 & 6.931 & 7.643 & 8.254 & 9.812 & 11.802 & 13.472 \\
\hline Exogenous R\&D & 6.187 & 6.932 & 7.646 & 8.259 & 9.823 & 11.819 & 13.488 \\
\hline$\% \Delta$ Endog. vs. Exog. & & $-0.01 \%$ & $-0.04 \%$ & $-0.06 \%$ & $-0.11 \%$ & $-0.14 \%$ & $-0.12 \%$ \\
\hline \multicolumn{8}{|l|}{ Control Rate } \\
\hline Endogenous R\&D & $\mathrm{N} / \mathrm{A}$ & $3.2 \%$ & $4.2 \%$ & $5.4 \%$ & $9.1 \%$ & $15.4 \%$ & $18.8 \%$ \\
\hline Exogenous R\&D & $\mathrm{N} / \mathrm{A}$ & $3.1 \%$ & $4.2 \%$ & $5.3 \%$ & $9.0 \%$ & $15.2 \%$ & $18.7 \%$ \\
\hline$\% \Delta$ Endog. vs. Exog. & & $0.44 \%$ & $0.89 \%$ & $1.08 \%$ & $1.14 \%$ & $0.80 \%$ & $0.52 \%$ \\
\hline \multicolumn{8}{|c|}{ Atmospheric Temperature -- degrees change C from 1990} \\
\hline No Policy & 0.430 & 0.491 & 0.635 & 0.822 & 1.477 & 2.595 & 3.946 \\
\hline Endogenous R\&D & 0.430 & 0.491 & 0.635 & 0.818 & 1.449 & 2.492 & 3.633 \\
\hline Exogenous R\&D & 0.430 & 0.491 & 0.635 & 0.818 & 1.449 & 2.493 & 3.636 \\
\hline$\% \Delta$ Endog. vs. Exog. & & $0.00 \%$ & $0.00 \%$ & $0.00 \%$ & $0.00 \%$ & $-0.04 \%$ & $-0.08 \%$ \\
\hline \multicolumn{8}{|l|}{$\begin{array}{l}\text { Output -- trillions } \$ 1990 \text { US } \\
\text { dollars }\end{array}$} \\
\hline No Policy & 22.61 & 30.00 & 36.95 & 43.73 & 63.60 & 95.32 & 159.06 \\
\hline Endogenous R\&D & 22.61 & 30.01 & 36.93 & 43.69 & 63.47 & 95.09 & 159.87 \\
\hline Exogenous R\&D & 22.61 & 30.01 & 36.92 & 43.67 & 63.41 & 94.94 & 159.64 \\
\hline$\% \Delta$ Endog. vs. Exog. & & $0.00 \%$ & $0.02 \%$ & $0.05 \%$ & $0.10 \%$ & $0.16 \%$ & $0.15 \%$ \\
\hline \multicolumn{8}{|c|}{ Consumption -- trillions $\$ 1990$ US dollars } \\
\hline No Policy & 16.40 & 22.25 & 27.68 & 32.98 & 48.38 & 72.52 & 119.56 \\
\hline Endogenous R\&D & 16.40 & 22.28 & 27.70 & 33.00 & 48.38 & 72.53 & 120.51 \\
\hline Exogenous R\&D & 16.40 & 22.29 & 27.71 & 33.00 & 48.37 & 72.50 & 120.39 \\
\hline$\% \Delta$ Endog. vs. Exog. & & $-0.04 \%$ & $-0.03 \%$ & $-0.02 \%$ & $0.01 \%$ & $0.05 \%$ & $0.10 \%$ \\
\hline
\end{tabular}




\section{Table 4 - Key Variables - Emissions Restricted to 1995 Levels}

\begin{tabular}{|c|c|c|c|c|c|c|}
\hline & 1995 & 2005 & 2015 & 2025 & 2055 & 2105 \\
\hline \multicolumn{7}{|l|}{ Carbon Tax (\$/ton) } \\
\hline Endogenous R\&D & $\mathrm{N} / \mathrm{A}$ & $\$ 366.07$ & $\$ 755.57$ & $\$ 1,135.20$ & $\$ 2,253.90$ & $\$ 3,978.32$ \\
\hline Exogenous R\&D & $\mathrm{N} / \mathrm{A}$ & $\$ 369.34$ & $\$ 760.33$ & $\$ 1,142.59$ & $\$ 2,272.24$ & $\$ 4,021.23$ \\
\hline$\% \Delta$ Endog. vs. Exog. & & $-0.89 \%$ & $-0.63 \%$ & $-0.65 \%$ & $-0.81 \%$ & $-1.07 \%$ \\
\hline \multicolumn{7}{|c|}{ Energy R\&D -- billions 1990 US dollars } \\
\hline Endogenous R\&D & 10.00 & 14.11 & 18.53 & 22.15 & 31.28 & 46.95 \\
\hline Exogenous R\&D & 10.00 & 13.14 & 16.90 & 19.86 & 26.91 & 38.93 \\
\hline Elasticity & N/A & 0.09 & 0.09 & 0.09 & 0.11 & 0.14 \\
\hline \multicolumn{7}{|l|}{ Emissions -- billion tons } \\
\hline No Policy & 6.187 & 7.157 & 7.982 & 8.722 & 10.791 & 13.943 \\
\hline Endogenous R\&D & 6.187 & 6.187 & 6.187 & 6.187 & 6.187 & 6.187 \\
\hline Exogenous R\&D & 6.187 & 6.187 & 6.187 & 6.187 & 6.187 & 6.187 \\
\hline$\% \Delta$ Endog. vs. Exog. & & $0.00 \%$ & $0.00 \%$ & $0.00 \%$ & $0.00 \%$ & $0.00 \%$ \\
\hline \multicolumn{7}{|l|}{ Control Rate } \\
\hline Endogenous R\&D & $\mathrm{N} / \mathrm{A}$ & $13.6 \%$ & $22.5 \%$ & $29.1 \%$ & $42.7 \%$ & $55.6 \%$ \\
\hline Exogenous R\&D & $\mathrm{N} / \mathrm{A}$ & $13.6 \%$ & $22.5 \%$ & $29.1 \%$ & $42.7 \%$ & $55.6 \%$ \\
\hline$\% \Delta$ Endog. vs. Exog. & & $0.00 \%$ & $0.00 \%$ & $0.00 \%$ & $0.00 \%$ & $0.00 \%$ \\
\hline \multicolumn{7}{|c|}{ Atmospheric Temperature -- degrees change C from 1990} \\
\hline No Policy & 0.430 & 0.491 & 0.635 & 0.822 & 1.477 & 2.595 \\
\hline Endogenous R\&D & 0.430 & 0.491 & 0.635 & 0.806 & 1.331 & 2.095 \\
\hline Exogenous R\&D & 0.430 & 0.491 & 0.635 & 0.806 & 1.331 & 2.095 \\
\hline$\% \Delta$ Endog. vs. Exog. & & $0.00 \%$ & $0.00 \%$ & $0.00 \%$ & $0.00 \%$ & $0.00 \%$ \\
\hline \multicolumn{7}{|l|}{$\begin{array}{l}\text { Output -- trillions } \$ 1990 \text { US } \\
\text { dollars }\end{array}$} \\
\hline No Policy & 22.61 & 30.00 & 36.95 & 43.73 & 63.60 & 95.32 \\
\hline Endogenous R\&D & 22.61 & 29.99 & 36.73 & 43.28 & 62.35 & 92.94 \\
\hline Exogenous R\&D & 22.61 & 29.99 & 36.71 & 43.24 & 62.23 & 92.66 \\
\hline$\% \Delta$ Endog. vs. Exog. & & $0.00 \%$ & $0.06 \%$ & $0.10 \%$ & $0.19 \%$ & $0.30 \%$ \\
\hline \multicolumn{7}{|c|}{ Consumption -- trillions $\$ 1990$ US dollars } \\
\hline No Policy & 16.40 & 22.25 & 27.68 & 32.98 & 48.38 & 72.52 \\
\hline Endogenous R\&D & 16.40 & 22.37 & 27.70 & 32.88 & 47.83 & 71.36 \\
\hline Exogenous R\&D & 16.40 & 22.39 & 27.72 & 32.89 & 47.81 & 71.28 \\
\hline$\% \Delta$ Endog. vs. Exog. & & $-0.09 \%$ & $-0.05 \%$ & $-0.02 \%$ & $0.04 \%$ & $0.11 \%$ \\
\hline
\end{tabular}




\section{Appendix A - Equations of the ENTICE Model}

This appendix presents the complete equations of the ENTICE model.

Exogenous variables and parameters

$t=$ time

$L_{t}=$ population at time $t$, also equal to labor inputs

$L_{0}=$ initial population level

$g_{L, t}=$ growth rate of population

$g_{L, 0}=$ initial value of the growth rate of population

$d_{L}=$ rate of decline of $g_{L, t}$

$R_{t}=$ pure time preference discount factor

$r_{0}=$ initial value of the pure rate of social time preference

$g_{r}=$ growth rate of the social time preference

$A_{t}=$ total factor productivity

$A_{0}=$ initial value of total factor productivity

$g_{L, t}=$ growth rate of total factor productivity

$g_{L, 0}=$ initial value of the growth rate of total factor productivity

$d_{L}=$ rate of decline of $g_{A, t}$

$\gamma=$ elasticity of output with respect to capital

$\beta=$ elasticity of output with respect to energy/carbon inputs

$\Phi_{t}=$ ratio of carbon emissions per unit of carbon services

$g_{t}^{z}=$ growth rate of $\Phi_{t}$ per decade

$\delta=$ rate of decline of $g_{t}^{z}$

$\zeta_{1}, \zeta_{2}, \zeta_{3}=$ parameters of the long-run carbon supply curve

markup $=$ energy services price markup

$\mathrm{CumC}^{*}=$ Total carbon resources available

$\delta=$ rate of depreciation of the physical capital stock

$\delta_{H}=$ rate of depreciation of energy knowledge stock

crowdout $=$ percentage of overall R\&D crowded out by energy $\mathrm{R} \& \mathrm{D}$

$a, b, \phi=$ parameters of the innovation possibilities curve

$\alpha_{H}=$ scaling factor for the stock of energy knowledge

$\alpha_{\Phi}=$ percentage of exogenous carbon intensity reduction

$\rho=$ substitution parameter for energy and knowledge

$L U_{t}=$ Land-use carbon emissions

$L U_{0}=$ Initial land-use carbon emissions

$\delta_{L U}=$ Rate of decline of land-use carbon emissions

$\phi_{11}, \phi_{12}, \phi_{21}, \phi_{22}, \phi_{23}, \phi_{32}, \phi_{33}=$ Parameters of the carbon transition matrix

$O_{t}=$ Increase in radioactive forcing over preindustrial levels due to exogenous anthropogenic causes

$\sigma_{1}, \sigma_{2}, \sigma_{3}=$ Temperature dynamics parameters

$4.1 / \lambda=$ Climate sensitivity - equilibrium increase in temperature from a doubling of $\mathrm{CO}_{2}$ concentrations) 


\section{Endogenous Variables}

$U_{t}=$ utility in period $t$

$c_{t}=$ per capita consumption

$Q_{t}=$ output (trillions of 1990 US dollars)

$\mu_{t}=$ emissions control rate in DICE model

$K_{t}=$ physical capital stock (trillions of 1990 US dollars)

$E_{t}=$ energy inputs

$p_{F}=$ price of fossil fuels

$F_{t}=$ fossil fuel/carbon inputs, also equal to $\mathrm{CO}_{2}$ emissions

$q_{F}=$ marginal cost of fossil fuel extraction

$\mathrm{CumC}_{t}=$ cumulative carbon extractions by year $t$

$I_{t}=$ investment in physical capital

$C_{t}=$ total consumption

$H_{E_{t}}=$ stock of energy knowledge

$R_{E_{t}}=$ energy $\mathrm{R} \& \mathrm{D}$

$E M_{t}=$ Carbon emissions

$M_{A, t}=$ Atmospheric $\mathrm{CO}_{2}$ concentration

$M_{U, t}=$ Upper oceans/biosphere $\mathrm{CO}_{2}$ concentration

$M_{L, t}=$ Lower oceans $\mathrm{CO}_{2}$ concentration

$F O R C E_{t}=$ Radioactive forcing, increase over preindustrial level

$T_{t}=$ Atmospheric temperature, increase over 1900 level

$T L_{t}=$ Lower ocean temperature, increase over 1900 level

The ENTICE model maximizes per capita utility, defined in equation (A 1) below, subject to a set of environmental and economic constraints. Economic constraints are represented by equations (A 2) - (A 17). Equations (A 18) - (A 26) are the environmental constraints.

$$
\max V=\sum_{t=0}^{T} U[c(t), L(t)] R(t)
$$

Economic Constraints

$$
R(t)=\prod_{v=0}^{t}\left[1+r_{0} e^{-g_{r} t}\right]^{10}
$$

$$
Q_{t}=A_{t} K_{t}^{\gamma} L_{t}^{1-\gamma-\beta} E_{t}^{\beta}-p_{F} F_{t}
$$

$K_{t}=\left(I_{t}-4^{*}\right.$ crowdout $\left.* R_{E, t}\right)-\delta K_{t-1}$.

$$
Q_{t}=C_{t}+I_{t} \text {. }
$$

$$
L_{t}=L_{0} \exp \left(g_{L, t}\right)
$$


(A 7) $\quad g_{L, t}=\left(g_{L, 0} / d_{L}\right) *\left(1-\exp \left(-d_{L} * t\right)\right)$

(A 8) $\quad A_{t}=A_{0} \exp \left(g_{A, t}\right)$

(A 9) $\quad g_{A, t}=\left(g_{A, 0} / d_{A}\right) *\left(1-\exp \left(-d_{A} * t\right)\right)$

(A 10)

$$
\begin{gathered}
E_{t}=\left[\alpha_{H} H_{E, t}^{\rho}+\left(\frac{F_{t}}{\alpha_{\Phi} \Phi_{t}}\right)^{\rho}\right]^{1 / \rho}, \quad \rho \leq 1 \\
\Phi_{t}=\exp \left[\left(\frac{g_{t}^{z}}{\delta^{z}}\right)\left(1-\exp \left(-\delta^{z} t\right)\right)\right]
\end{gathered}
$$

(A 11) $\quad P_{F}=q_{F}+$ markup

(A 12) $\quad q_{F}=\zeta_{1}+\zeta_{2}\left[\text { Cum }_{t} / \text { Cum }^{*}\right]^{\zeta_{3}}$

(A 13) $\quad \quad \quad \quad$ um $C_{t}=\operatorname{CumC}_{t-1}+10^{*} F_{t}$

(A 14) $\quad F_{t}<0.1 *\left(\right.$ CarbMax $\left.-\mathrm{CumC}_{t}\right) / 10$

(A 15) $\quad H_{E, t}=h\left(R_{E, t}\right)+\left(1-\delta_{H}\right) H_{E, t-1}, \quad i=A, E$

(A 16) $\quad h\left(R_{E, t}\right)=a R_{E, t}^{b} H_{E, t}^{\phi}$

(A 17) $\quad Q_{t}=C_{t}+I_{t}+R_{E_{t}}$

Environmental Constraints
(A 18)
$L U_{t}=L U_{0}\left(1-\delta_{L U}\right)^{t}$
(A 19)
$E M_{t}=F_{t}+L U_{t}$
(A 20)
$M_{A, t}=10^{*} E M_{t}+\phi_{33} M_{L, t-1}+\phi_{23} M_{U, t-1}$
(A 21)
$M_{L, t}=\phi_{11} M_{A, t-1}+\phi_{21} M_{U, t-1}$
(A 22)
$M_{U, t}=\phi_{12} M_{A, t-1}+\phi_{22} M_{U, t-1}+\phi_{32} M_{L, t-1}$
(A 23)
FORCE $_{t}=4.1^{*}\left\{\log \left(M_{A, t} / 596.4\right) / \log (2)\right\}+O_{t}$
(A 24)
$O_{t}=-0.1965+0.13465 t$,
$t<11$
$O_{t}=1.15$,
$t \geq 11$
(A 25)
$T_{t}=T_{t-1}+\sigma_{1}\left\{F O R C E_{t}-\lambda T_{t-1}-\sigma_{2}\left(T_{t-1}-T L_{t-1}\right)\right\}$
(A 26)
$T L_{t}=T L_{t-1}+\sigma_{3}\left(T_{t-1}-T L_{t-1}\right)$ 


\section{Appendix B - Calibration of the ENTICE Model}

This appendix describes the steps taken to calibrate the ENTICE model. As a global macroeconomic model, ENTICE uses Nordhaus' DICE model (2000) as its basic building block. Since the current version of Nordhaus' DICE model does not include carbon emissions as an input, but rather simply models emissions as a byproduct of output requiring control, the first step to constructing the model is to add a fossil fuel sector that mimics the behavior of the original DICE model. I do this using the same modeling structure as Nordhaus' RICE model, except that I apply the equations at a global, rather than regional, level. Key equations of the economic sector of the DICE model, along with the modifications necessary to include carbon emissions as an input, are included in the modeling appendix. I calibrate this basic model, with no energy R\&D, so that the results are comparable to Nordhaus' DICE model. To begin, I take the initial value of $F$ from the latest version of the DICE model. I then solve for initial values of $A$ and $K$ that reproduce the initial output found in the DICE model. Next, I calculate the elasticity of output to with respect to energy, $\beta$, as the percentage of output spent on fossil fuels in the initial period, using the 1995 price of carbon based on equations (6) and (7). ${ }^{34}$ Finally, the growth rate of $\Phi, g^{z}(-15.49)$, and the rate of decline of this growth rate, $\gamma^{z}(23.96)$, are chosen to produce an emissions path as close as possible to the DICE model. These values represent the rate of exogenous decline in carbon intensity without any energy R\&D in the model. Figures B1 and B2 compares the emissions and output that result from this calibration.

Having added carbon fuels as an input to production in the DICE model, the next step is to add induced technological change to the ENTICE model. The modeling for this stage is

\footnotetext{
${ }^{34}$ References to equation numbers refer to equations in the text of the main paper.
} 
described the main text of the paper. Calibration requires choosing values for the following parameters:

- the initial value of energy research, $R_{E 0}$.

- $\rho$, the substitution parameter in equation (10),

- parameters in the invention possibilities frontier (9): $a, b$, and $\phi$, and

- the initial level of energy human capital, $H_{E 0},{ }^{35}$

- $\alpha_{H}$, the scaling factor for the effect of this human capital, and

- $\alpha_{\Phi}$, the percentage of exogenous technological change remaining.

To calibrate the energy R\&D sector, three goals must be met. First, R\&D levels should be consistent with historical levels. A starting value of $\$ 10$ billion is chosen for the base year of 1995. To get this value, I begin with an estimated level of total global spending on R\&D of $\$ 500$ billion. This figure is based largely on data from OECD countries. Energy R\&D data is not available on a global basis. However, it is available for the United States. In the U.S., two percent of R\&D spending in 1995 went to energy-related $R \& D$. The $\$ 10$ billion figure used in this paper is simply two percent of the global level of R\&D. This figure is also close to the initial value of R\&D used by Nordhaus (2002).

Second, the behavior of energy R\&D should be consistent with empirical studies both across time and across policy dimensions. Based on Popp (2002), I use an elasticity of energy R\&D with respect to energy prices of 0.35 for the base model. As the price of carbon rises over time, the time path of energy R\&D should follow the path predicted by this value as closely as possible. $^{36}$ In addition, elasticities of energy R\&D calculated on differences in the carbon price

\footnotetext{
${ }^{35}$ Note that, since human capital enters the invention possibilities frontier multiplicatively, the initial value cannot be zero.

${ }^{36}$ Note that, to account for growth in the level of economic activity, all elasticities are calculated based on a ratio of energy R\&D to global output.
} 
with and without a carbon tax in the optimal policy simulation should also equal 0.35 . Since the goal of this paper is to explore the consequences of omitting endogenous technological change from earlier climate change models, when these two goals are incompatible, the second takes precedence. Furthermore, since Popp (2002) also notes that energy R\&D experiences diminishing returns over time, the calibrated elasticity should fall over time. Figure B3 shows the calibrated levels of energy R\&D and what would be predicted by a constant elasticity over time of 0.35 . Figure 3 in the main text shows the elasticity across the policy outcomes.

Finally, Popp (2001) estimates a 4:1 ratio on the returns to energy R\&D. Thus, each dollar of energy R\&D should lead to a four dollar reduction in energy savings. The model is calibrated so that a weighted average of energy savings each period (weighted by the discount factors used in the model) produce a 4:1 ratio of energy savings to energy R\&D.

Using these goals as guidelines for choosing the parameters, I first choose the value of $H E_{0}$ to approximate baseline emissions in early years of the simulation. Next, I choose $\rho$ to approximate the elasticity of energy R\&D between the no-policy and optimal policy simulations. Third, the value of the scaling factor $\alpha_{H}$ is chosen to yield the appropriate rate of return on energy R\&D. To calibrate the inventions possibility frontier, the value $a$ is chosen so that the change in energy R\&D between 1995 and 2005 in the optimal policy simulation is consistent with the elasticity of 0.35 . Values of $b$ and $\phi$ are chosen so that future elasticities fit the desired time path - falling slowly in the near future due to diminishing returns to R\&D. Once the desired time path of R\&D is calibrated, the scaling factor $\alpha_{\Phi}$ can be adjusted to change the level of baseline emissions as appropriate. A value of 0.8 is used in the base model, meaning that 80 percent of exogenous technological change remains in the ENTICE model. As a result, purposeful R\&D efforts to improve energy efficiency are only a small portion of the changes that 
take place over time to reduce energy intensity. Table 1 in the paper presents a complete list of the parameter values chosen for both the base model and various sensitivity analysis scenarios. 
ENTICE: Endogenous Technological Change in the DICE Model of Global Warming

BD

Figure B1 - Industrial Emissions in the ENTICE \& RICE Models

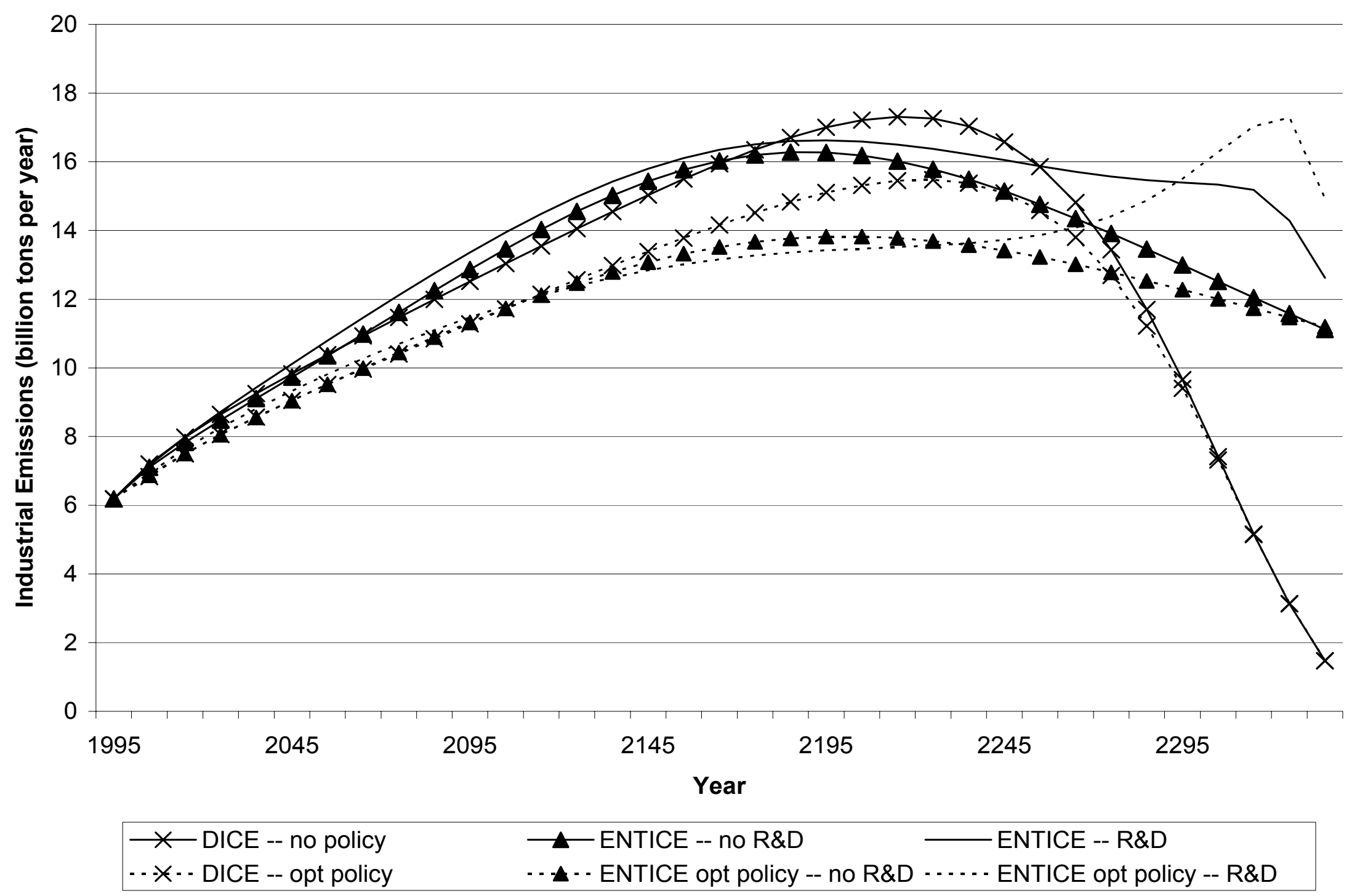


Figure B2 - Output in the ENTICE \& RICE Models

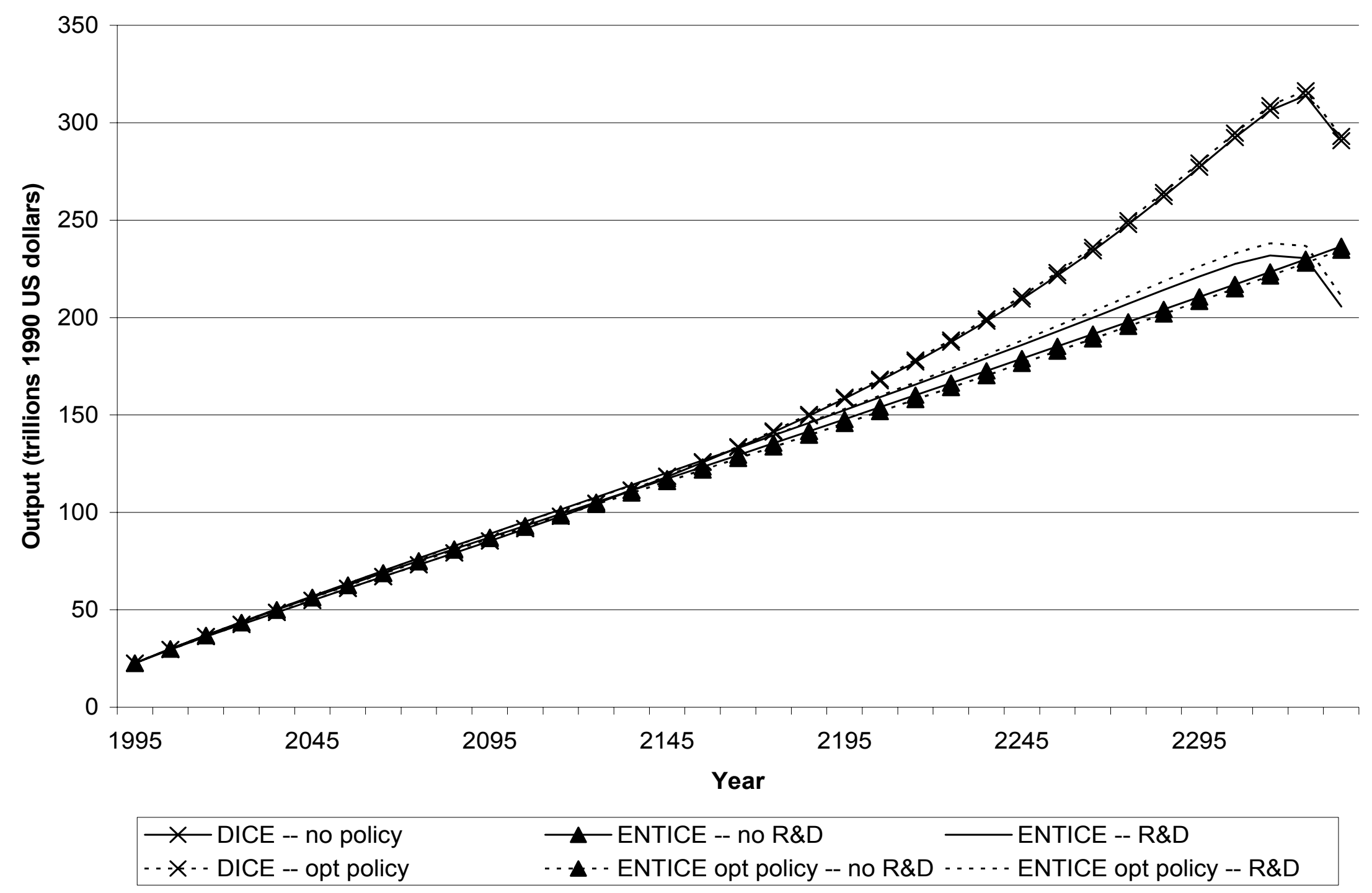


Figure B3 - Predicted and Actual Energy R\&D

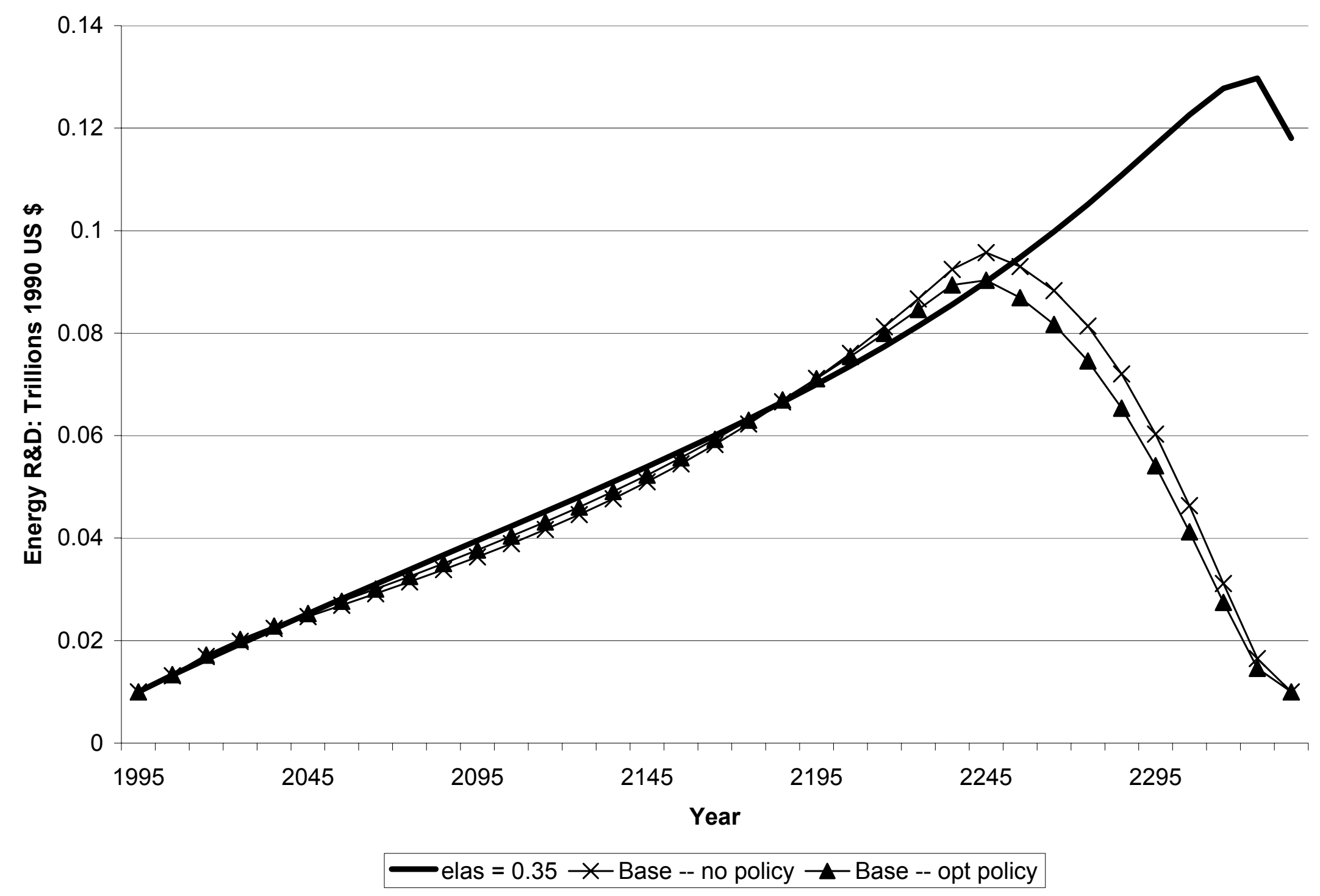

